\title{
Cation transporters/channels in plants: Tools for nutrient biofortification
}

Edgar Pinto, Isabel M.P.L.V.O. Ferreira

\begin{abstract}
Cation transporters/channels are key players in a wide range of physiological functions in plants, including cell signaling, osmoregulation, plant nutrition and metal tolerance. The recent identification of genes encoding some of these transport systems has allowed new studies toward further understanding of their integrated roles in plant. This review summarizes recent discoveries regarding the function and regulation of the multiple systems involved in cation transport in plant cells. The role of membrane transport in the uptake, distribution and accumulation of cations in plant tissues, cell types and subcellular compartments is described. We also discuss how the knowledge of inter- and intra-species variation in cation uptake, transport and accumulation as well as the molecular mechanisms responsible for these processes can be used to increase nutrient phytoavailability and nutrients accumulation in the edible tissues of plants. The main trends for future research in the field of biofortification are proposed.
\end{abstract}

\section{Abbreviations}

ACA, Ca ${ }^{2+}-A T P a s e ;$

$B C D$, Bush-and-chlorotic-dwarf;

$\mathrm{CAX}, \mathrm{Ca}^{2+} / \mathrm{H}^{+}$exchanger;

CDF,Cation diffusion facilitator;

CEC, Cation exchange capacity;

$\mathrm{CHX}$, Cation $/ \mathrm{H}^{+}$exchanger;

CNGC, Cyclic-nucleotide gated channel;

COPT, Copper transporter;

DA-NSCC, Depolarization-activated nonselective cation channel;

DMA, Deoxymugineic acid;

ECA, Endomembrane-type $\mathrm{Ca}^{2+}$-ATPase;

ENA, Efflux transporter of nicotianamine;

FRD, Ferric reductase defective;

FRDL, Ferric reductase defective-like;

FRO, Ferric-chelate reductase oxidase;

GLR, Ionotropic glutamate receptor;

GSH,Glutathione; 
HA, $\mathrm{H}^{+}$-ATPase;

HA-NSCC, Hyperpolarization-activated nonselective cation channel;

$\mathrm{HAK} / \mathrm{KT} / \mathrm{KUP}, \mathrm{K}^{+} / \mathrm{H}^{+}$symporters;

HATS, High-affinity transporter system;

HKT/Trk, $\mathrm{K}^{+} / \mathrm{Na}^{+}$symporters;

HMA, Heavy metal associated;

IREG/FPN, Iron-regulated/Ferroportin;

IRT, Iron-regulated transporter;

$\mathrm{KCO}$, Kir-like $\mathrm{K}^{+}$channel;

$\mathrm{KEA}, \mathrm{K}^{+}$efflux antiporter;

LATS, Low-affinity transporter system;

LCT, Low-affinity cation transporter;

MA, Mugineic acid;

MATE, Multidrug and toxic compound extrusion;

MRS2/MGT, Magnesium transporter;

$\mathrm{MHX}, \mathrm{Mg}^{2+} / \mathrm{H}^{+}$antiporter;

MIT, Mitochondrial transporter;

MT, Metallothionein;

MTP, Metal tolerance proteins;

NA, Nicotianamine;

$\mathrm{NHX}, \mathrm{Na}^{+} / \mathrm{H}^{+}$antiporter;

NRAMP, Natural resistance associated macrophage protein;

NSCC, Nonselective cation channel;

OM, Organic matter;

OPT, Oligopeptide transporter;

PC, Phytochelatin;

PCR, Plant cadmium resistance;

PEZ, Phenolics efflux zero;

PIC, Permease in chloroplast;

PS, Phytosiderophore;

RDA, Recommended dietary allowances;

TPC, Two-pore channel;

TPK, Two-pore $\mathrm{K}^{+}$channel;

TOM,Transporter of mugineic acid family phytosiderophores;

VI-NSCC, Voltage-insensitive nonselective cation channel;

VIT, Vacuolar iron transporter;

YS, Yellow stripe;

YSL,Yellow stripe-Like;

ZIF, Zinc-induced facilitator; 
ZIP, (ZRT-IRT)-like protein

\section{Keywords}

Cations; Transporter; Channel; Biofortification; Genetic engineering

\section{Introduction}

Plant cells contain several cations. Potassium $(\mathrm{K})$, calcium $(\mathrm{Ca})$ and magnesium $(\mathrm{Mg})$ are the major cationic species (Maathuis, 2009); iron (Fe), copper (Cu), manganese $(\mathrm{Mn})$, nickel $(\mathrm{Ni})$ and zinc $(\mathrm{Zn})$ are widely recognized to be trace essential cations (Pilon et al., 2009) and cobalt (Co) and sodium (Na) are known as "beneficial" elements (Pilon-Smits et al., 2009).

Each of the essential cations has a distinct specific role. Both $\mathrm{Ca}$ and $\mathrm{Mg}$ are constituents of organic structures, such as enzyme molecules, where they may be involved in the catalytic function of the enzymes (Maathuis, 2009). Potassium is one of the few cations that are not a component of organic structures. It is rather involved in the osmoregulation, the maintenance of electrochemical balance in cells and their compartments, and the regulation of the enzymatic activity (Wang and Wu, 2013). Due to their low concentration, trace essential cations do not play a direct role in osmoregulation or similar processes. These elements are redox-active and act as catalytically active cofactors in enzymes. Others have enzyme-activating functions, and others fulfill a structural role in stabilizing proteins (Hänsch and Mendel, 2009 and Pilon-Smits et al., 2009).

Cations must be acquired by plant roots from the soil solution and then delivered to tissues, organs and subcellular compartments, where they are required to support plants' metabolism (Maathuis, 2009). Plants face major variations in cation uptake, particularly in the case of trace essential (Fe, Zn, $\mathrm{Cu}, \mathrm{Ni}$ and $\mathrm{Mn}$ ) and beneficial (Co and $\mathrm{Na}$ ) cations. On the one hand, the phytoavailability of these elements can be low, resulting in deficiency symptoms of the plants that grown in such environments. On the other hand, toxicity can occur in certain environments were the phytoavailability of problematic elements (e.g., $\mathrm{Na}$ ) is enhanced by the conditions of that environment (Pinto et al., $2014 \mathrm{~b}$ and Pinto et al., 2015). Plants have to cope with variable demands of different tissues during growth or in response to abiotic stresses. Thus, along the course of evolution, plants have developed highly specialized homeostatic mechanisms that deal with systemic spatiotemporal requirements in the acquisition, transport and supply of cations to specific tissues, organs or compartments (Pinto et al., 2014a). 
It is been widely recognized that the distinct patterns in the uptake, distribution and accumulation of cations in plants is the result of selective transport processes in which membrane transport proteins are involved (Haferkamp and Linka, 2012). The identification of several gene families encoding putative cation transporters/channels constituted a major breakthrough in the plant science field enabling the realization of studies at the gene and protein levels (e.g., gene expression at the tissue or plant levels, transport activity and subcellular localization) to achieve a further understanding of the integrated roles of these transport systems in plants.

The list of essential minerals for plants is quite similar but not equal to the list for humans. For example, Se, I, Co and $\mathrm{Na}$ are essential for humans but not for most plants (White and Brown, 2010). Therefore, human deficiencies may arise for these elements in populations that depend on plants grown locally where the soil content of these elements is low. Actually, serious human deficiencies of Se and I exist worldwide (Hirschi, 2009). For nutrients required by both plants and humans, one can expect that human deficiencies will be less of a problem because the elements will necessarily be present in plant foods. However, the mineral content of plants is sometimes very low to meet human requirements, or the minerals may be present in forms that cannot be efficiently utilized by humans. Examples of both these situations are $\mathrm{Ca}$ and $\mathrm{Fe}$, respectively (Jeong and Guerinot, 2008 and Dayod et al., 2010). Thus, new strategies are needed to ensure a sustainable supply of healthy food to world's population while meeting human nutritional requirements.

The aim of this review is to join together information about the major cation transporters/channels involved in the uptake, distribution and accumulation of essential ( $\mathrm{K}, \mathrm{Ca}, \mathrm{Mg}, \mathrm{Fe}, \mathrm{Cu}, \mathrm{Mn}, \mathrm{Zn}$ and $\mathrm{Ni}$ ) and beneficial (Co and $\mathrm{Na}$ ) elements and how this information can be used in biofortification programs. In the following sections, a detailed description of the transporters/channels function will be provided taking into consideration the four major processes that elements usually undergo - (1) uptake, (2) root compartmentation, (3) translocation and (4) leaf compartmentation. To simplify, in each of these four processes the transporters/channels involved in cation transport will be described according to the following division: (i) macroelements ( $\mathrm{K}, \mathrm{Ca}$ and $\mathrm{Mg}$ ); (ii) trace essential elements ( $\mathrm{Fe}, \mathrm{Cu}, \mathrm{Mn}, \mathrm{Ni}$ and $\mathrm{Zn}$ ); and (iii) beneficial elements ( $\mathrm{Co}$ and $\mathrm{Na}$ ). Then, a careful description of pathways to improve the biofortification of plant foods will be provided. 


\section{Uptake}

Cation transport across the plant plasma membrane is mediated by an electrochemical gradient of protons generated by plasma membrane $\mathrm{H}^{+-}$ ATPases. This "primary transport system" pumps protons out of the cell creating $\mathrm{pH}$ and electrical potential differences across the plasma membrane (Fox and Guerinot, 1998). At that point, "secondary transport systems" can utilize these gradients for many plant functions such as nutrients influx and efflux (Palmgren, 2001). Cations enter the root either by crossing the plasma membrane of the root endodermal cells (symplastic transport) or by entering the root apoplast through the space between cells (apoplastic transport). They cannot pass through membranes without the aid of membrane transporter proteins. These transporter proteins occur naturally in several plant membranes (e.g., tonoplast, endoplasmic reticulum, mitochondria, chloroplasts) and, usually, multiple transporters exist for each element (Pinto et al., 2014a). For instance, rice (Oryza sativa) has at least seven Cu transporters ( Yuan et al., 2011). Each transporter has unique properties. When a low concentration of nutrients is present in the soil solution, their uptake usually requires the high-affinity transport system (HATS). By contrast, the low-affinity transport system (LATS) is used more when high concentrations of nutrients are present, such as in agricultural soils after fertilization. Furthermore, the abundance of each transporter varies with tissue type and environmental conditions, making the uptake of cations in plants a complex process ( Karley and White, 2009 and Puig and Penarrubia, 2009).

\section{Macroelements}

Potassium $(\mathrm{K})$ is the most abundant cation in plant cells and plays a vital role in plant growth and development. Normally, $\mathrm{K}$ content in soil solution ranges between 1 and $10 \mathrm{mM}$ whereas intracellular $\mathrm{K}$ levels are maintained at 100$200 \mathrm{mM}$. Therefore, $\mathrm{K}$ uptake from the soil is obviously against a concentration gradient (Anschutz et al., 2014 and Zörb et al., 2014). Similarly to most mineral nutrients, the main acquisition of $\mathrm{K}$ from the outside environment follows a biphasic form, defined as the sum of two distinguishable uptake mechanisms (HATS and LATS) at the root plasma membrane (Wang and Wu, 2013). Several genes appear to encode putative $\mathrm{K}$ transporters/channels in the plasma membrane of Arabidopsis root cells (Fig. 1). They are grouped into four families, including HAK/KT/KUP ( $\mathrm{K}^{+} / \mathrm{H}^{+}$symporters), HKT/Trk ( $\mathrm{K}^{+} / \mathrm{Na}^{+}$symporters), $\mathrm{CHX}$ (cation/ $\mathrm{H}^{+}$antiporters) and Shaker channels (Nieves-Cordones et al., 2014). The bulk of HATS that mediate the influx of $K$ are catalyzed by members of the HAK/KT/KUP family (Very et al., 2014). In Arabidopsis, 10 of 13 AtKT/KUPs are 
expressed in root hairs. Five of them were expressed in root tip cells suggesting an essential role of these HATS in K uptake (Ahn et al., 2004). From these 5 AtKT/KUPs expressed in Arabidopsis roots, AtKUP1, AtKUP4 and AtHAK5 are transporters in the plasma membrane of root cells that seem to be engaged in the K influx (Ahn et al., 2004, Fulgenzi et al., 2008 and Rubio et al., 2008). The physiological importance of HKT/Trk transporters for high-affinity $\mathrm{K}$ influx is not yet fully clear. Several plant studies have pointed out that most of HKT transporters function as $\mathrm{Na}$ transporters and only a limited number of these transporters are $\mathrm{Na}^{+} / \mathrm{K}^{+}$symporters. Therefore, evidence supports a restricted role of the HKT family in K uptake (Very et al., 2014). Several members of the $\mathrm{CHX}$ family have been identified as $\mathrm{K}$ transporters. For example, AtCHX13 and AtCHX17 have been proposed as possible pathways for root $\mathrm{K}$ influx (Cellier et al., 2004 and Zhao et al., 2008). Low-affinity $\mathrm{K}$ influx seems to be mediated by Shaker K-channels such as AtAKT1 and AtKC1, which are mainly expressed in root epidermal cells (Geiger et al., 2009, Ardie et al., 2010 and Jeanguenin et al., 2011). Plant Shaker channels display extraordinary K selectivity.

Consequently, the Shaker K-channels AtAKT1 and AtKC1 as well as the $\mathrm{HAK} / \mathrm{KT} / \mathrm{KUP}$ transporter AtHAK5 are responsible for almost all $\mathrm{K}$ influx (Nieves-Cordones et al., 2014). 


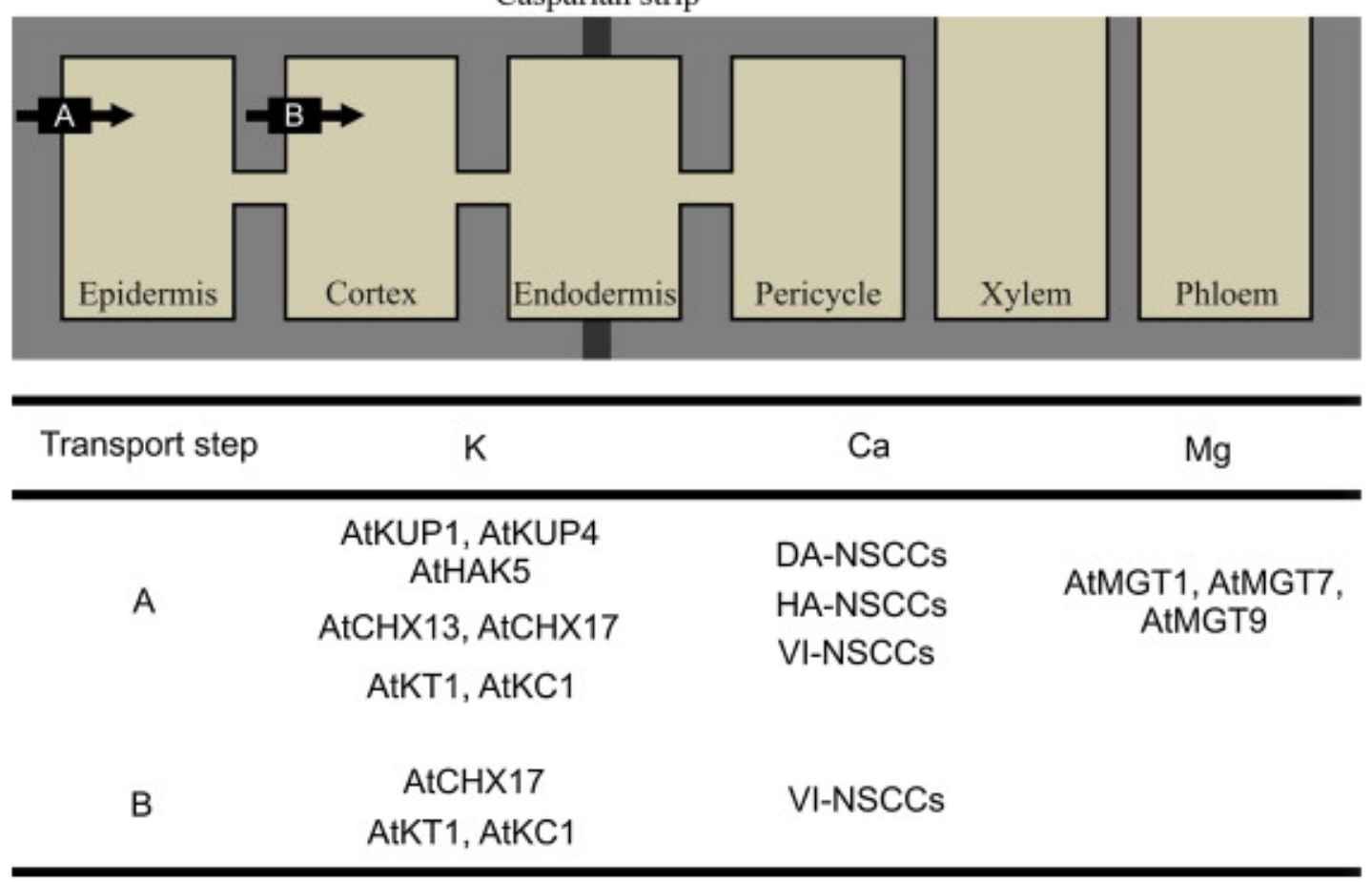

Fig. 1

Schematic illustration of some of the key transport steps for the uptake of $\mathrm{K}$, Ca and $\mathrm{Mg}$ in the plant (Arabidopsis thaliana was used as model plant). The proteins identified for mediating some of these transport functions are given in the table below. The arrows indic ate the direction of transport and each letter in the figure corresponds to the list given in the first column of the table.

A peculiar electrochemical gradient exists for $\mathrm{Ca}$ in plant roots since cytosolic Ca levels are in the sub- $\mu \mathrm{M}$ range, while Ca concentrations in the soil solution are in the $\mathrm{mM}$ range (Karley and White, 2009). Calcium is taken up symplastically through nonselective cation channels (NSCCs) present in the root system. These can be divided according to their voltage dependence into depolarization-activated (DA-NSCCs), hyperpolarization-activated (HA-NSCCs) and voltage-insensitive (VI-NSCCs) types, as shown in Fig. 1(Demidchik and Maathuis, 2007). Regarding HA-NSCCs, members of the annexin gene family are likely to encode these Ca channels (Mortimer et al., 2008). For VI-NSCCs, two gene families, the plasma membrane-localized cyclic-nucleotide gated channels (CNGC) and the ionotropic glutamate receptor (GLR) homologues are proposed to mediate Ca uptake (Ma et al., 2009, Swarbreck et al., 2013 and Forde, 2014). Despite the type of NSCC used to mediate Ca influx, the opening of these channels must be tightly regulated, because changes in cytosolic Ca levels trigger several specific responses to many environmental and developmental stimuli (McAinsh and Pittman, 2009). 
Magnesium concentration in soil solutions normally ranges from 8.5 to $125 \mathrm{mM}$. Cytosolic Mg levels are around $0.4 \mathrm{mM}$, thus $\mathrm{Mg}$ influx into root cells can be achieved by Mg-permeable cation channels (Karley and White, 2009). Despite that, members of the MRS2/MTG gene family expressed in Arabidopsis appear to dominate the Mg uptake across the root plasma membrane (Fig. 1) (Gebert et al., 2009). A member of theArabidopsis thaliana Mg transport family, AtMGT1, was expressed in tobacco (Nicotiana benthamiana) and showed an increased Mg content ( Deng et al., 2006). In addition to AtMGT1, other two MRS2/MTG members, AtMGT7 and AtMGT9, are expressed in Arabidopsis roots and have a key role in Mg uptake ( Mao et al., 2008 and Chen et al., 2009).

\section{Trace essential elements}

Several Fe species may be taken up by plant roots. The divalent form $\left(\mathrm{Fe}^{2+}\right)$ is the main absorbed species but $\mathrm{Fe}^{3+}$ and Fe-chelates are also taken up. Plants have developed several mechanisms to enhance Fe uptake. Two main categories can be distinguished according to the plant species: Strategy I in non-graminaceous plants and Strategy II in graminaceous plants (Fig. 2). The main processes of Strategy I (used by non-graminaceous plants such as $A$. thaliana) are the excretion of protons and phenolic compounds from the roots to the rhizosphere, reduction of ferric chelates at the root surface, and the absorption of the resulting ferrous ions across the root by plasma membrane transporters ( Kobayashi and Nishizawa, 2012). The $\mathrm{H}^{+}-\mathrm{ATPase}$ (HA) transporters are responsible for the efflux of protons to promote the acidification of the rhizosphere (Santi and Schmidt, 2009) and the recently identified OsPEZ1 and OsPEZ2 (phenolics efflux zero) seems to be involved in the secretion of phenolics ( Bashir et al., 2011a and Ishimaru et al., 2011). Nongraminaceous plants depend on ferric reductase oxidase (e.g., AtFRO2) to reduce the ferric chelates at the root surface (Jeong and Connolly, 2009) and then on the iron-regulated transporter (AtIRT1, AtIRT2 and AtIRT3) to absorb the generated $\mathrm{Fe}^{2+}$ ions across the root plasma membrane ( Lin et al., 2009, Vert et al., 2009 and Barberon et al., 2011). The Strategy II, used by graminaceous plants (e.g., barley, maize and rice), depends on the biosynthesis and secretion of phytosiderophores (PS) such as mugineic acids (MAs) which mobilize Fe (Kobayashi and Nishizawa, 2012). Recently, the gene responsible for MA secretion was identified to be the transporter of the mugineic acid family phytosiderophores 1 (OsTOM1 and HVTOM1, for rice and barley, respectively) (Nozoye et al., 2011). The MAs secreted into the rhizosphere stimulate the solubilization of $\mathrm{Fe}^{3+}$ in the soil and the resulting Fe-PS complexes can be taken 
up through Yellow Sripe (YS) and Yellow Stripe-like (YSL) transporters such as HvYS1, ZmYS1 and OsYSL15 ( Murata et al., 2008, Inoue et al., 2009, Ueno et al., 2009 and Nozoye et al., 2013). Despite being Strategy II plants, graminaceous plants (e.g., rice), can also have ferrous transporters (e.g., OsIRT1, OsNRAMP1 and OsNRAMP5) allowing the absorption of $\mathrm{Fe}^{2+}$ in addition to its Strategy II-based Fe ${ }^{3+}-\mathrm{MA}$ uptake ( Takahashi et al., 2011 and Ishimaru et al., 2012).

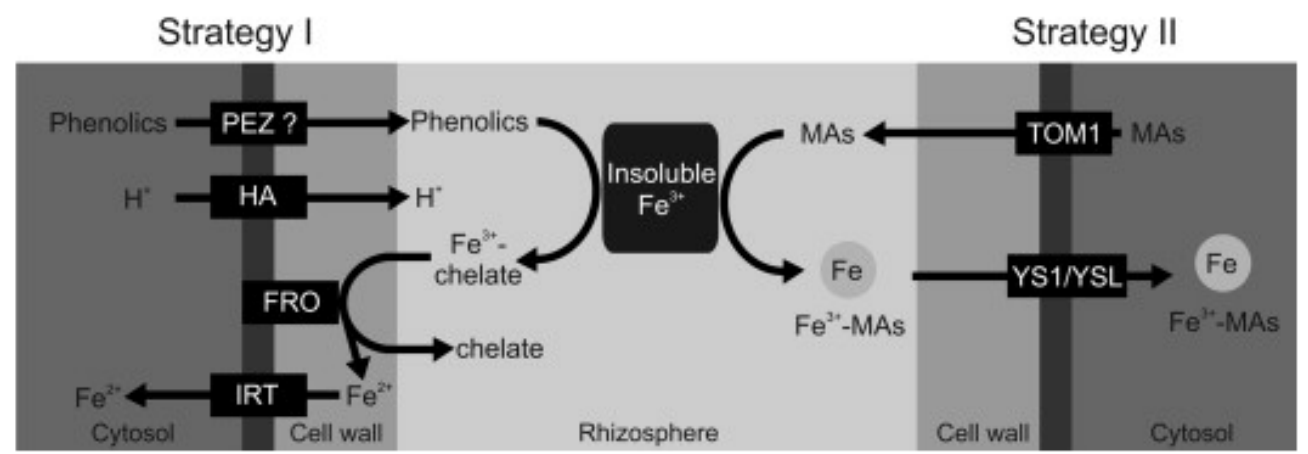

Fig. 2 .

Fe acquisition strategies in plants: (left) Strategy I in non-graminaceous plants and (right) Strategy II in graminaceous plants (right). Black boxes represent the transporters and enzymes that play essential roles in these strategies.

The most bioavailable form of $\mathrm{Cu}$ in soils is $\mathrm{Cu}^{2+}$. However, root uptake is often facilitated by reduction of $\mathrm{Cu}^{2+}$ to $\mathrm{Cu}^{+}$. The ferric reductase oxidases AtFRO2, AtFRO3, AtFRO4 and AtFRO5, expressed in A. thaliana, seem to be involved in this process (Mukherjee et al., 2006 and Bernal et al., 2012). Copper is likely to enter the cytosol of root cells through a cell surface COPT/Ctr-family transporter. Six members of the Ctr family (COPT1-6) which mediate the influx of $\mathrm{Cu}$ have been identified in Arabidopsis. AtCOPT1, AtCOPT2 and AtCOPT3 are expressed in the plasma membrane of roots and have an important role in the acquisition of Cu monovalent ions (Fig. 3) ( Yamasaki et al., 2009 and Andres-Colas et al., 2010). Furthermore, members of the ZincRegulated Transporter and Iron-Regulated Transporter (ZRT-IRT)-like proteins (ZIP) family can also mediate the uptake and transport of $\mathrm{Cu}$ in Arabidopsis ( Yamasaki et al., 2009 and del Pozo et al., 2010). Members of the YS and YSL family (e.g., ZmYS1 and HvYSL2) are also involved in the transport of Cu-PS complexes ( Murata et al., 2008 and Araki et al., 2011). 


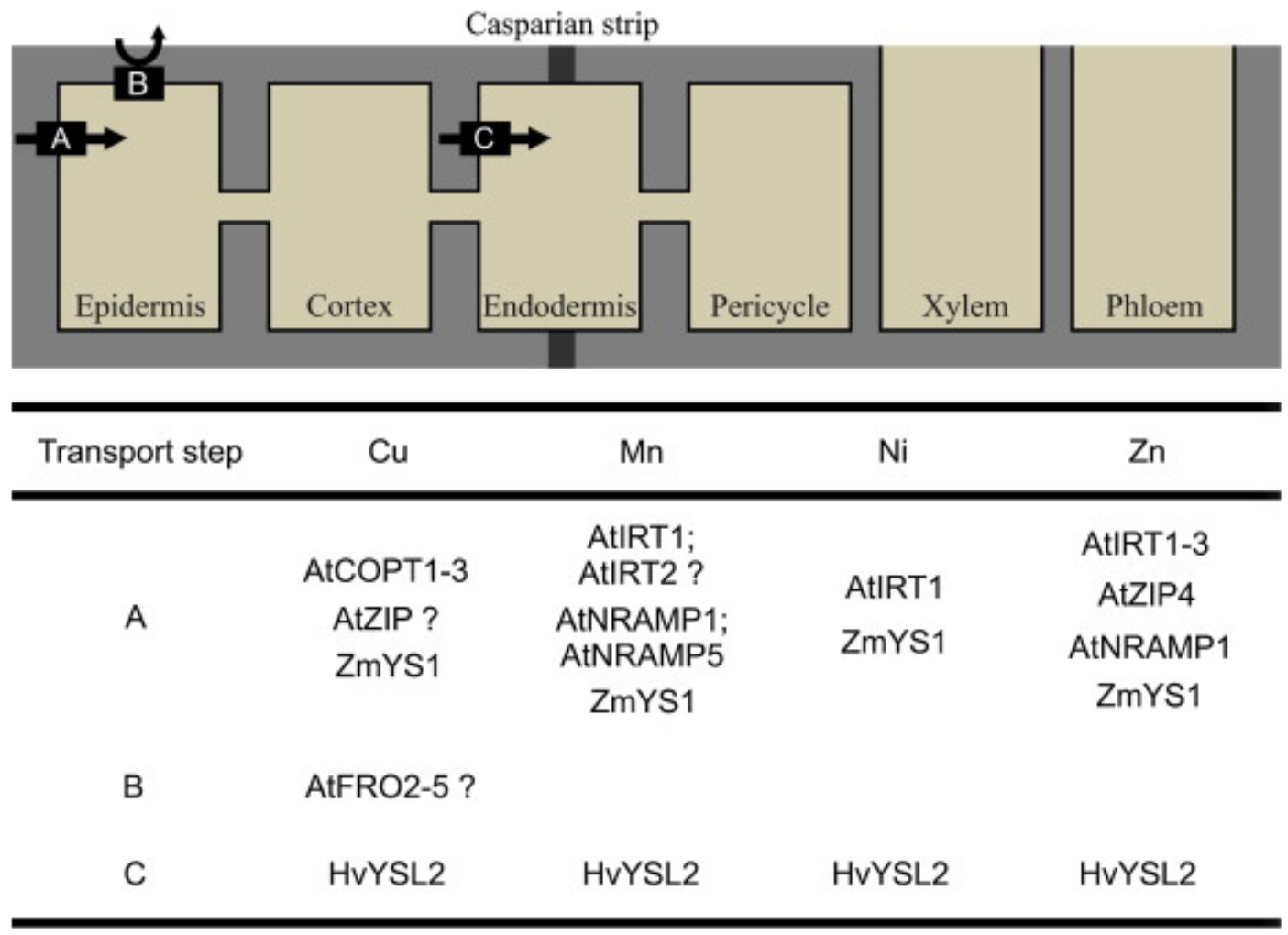

Fig. 3 .

Schematic illustration of some of the key transport steps for the uptake and reduction of $\mathrm{Cu} \mathrm{Mn,} \mathrm{Ni} \mathrm{and} \mathrm{Zn}$ in the plant (Arabidopsis thaliana, Zea mays and Hordeum vulgare were used as model plants). The proteins identified for mediating some of these transport/reductive functions are given in the table below. The arrows indic ate the direction of transport/reduction and each letter in the figure corresponds to the list given in the first column of the table.

The oxidized forms $\mathrm{Mn}^{3+}$ and $\mathrm{Mn}^{4+}$ are not bioavailable to plants. It is the reduced form of this element, $\mathrm{Mn}^{2+}$, that is absorbed by root cells (Pittman, 2005). The plasma membrane IRT1, expressed in both Arabidopsis and barley, can transport Mn (Fig. 3) (Pedas et al., 2008 and Barberon et al., 2011). The overexpression of AtIRT2 leads to overaccumulation of $\mathrm{Mn}$ in transgenic plants, but the role of this transporter in Mn uptake remains to be clarified (Vert et al., 2009). The plasma membrane-localized NRAMP1 and NRAMP5 were shown to be high-affinity $\mathrm{Mn}$ transporters in Arabidopsis and rice, respectively. Both AtNRAMP1 and OsNRAMP5 have broad selectivity, and their expression is restricted to the root (Cailliatte et al., 2010 and Ishimaru et al., 2012). In maize and barley, Mn uptake can also be performed by the ZmYS1 and HvYSL2 transporters, respectively, which were confirmed to be capable of acquiring MnPS complexes from the rhizosphere (Murata et al., 2008 and Araki et al., 2011). Nickel is present in the environment usually in the form of $\mathrm{Ni}^{2+}$, which is the most available form to plants. Divalent cations such as $\mathrm{Ni}, \mathrm{Cu}$ and Fe have very similar physicochemical properties thus they compete with each other in 
biochemical and physiological processes in plants (Ghasemi et al., 2009). Nickel can enter symplastically into the root cells through AtIRT1 (Nishida et al., 2012). Moreover, Ni can also be taken up in the form of Ni-PS complexes by the ZmYS1 due to its broad selectivity for several cations (Fig. 3) (Murata et al., 2008).

Zinc is taken up across the plasma membrane of root cells as a free ion and/or complexed with PS (Sinclair and Kramer, 2012). The ZIP transporter family includes the best candidates for facilitating $\mathrm{Zn}$ influx into the plant cytoplasm. In addition to its role in Fe acquisition, the broad selectivity of AtIRT1 allows this transporter to mediate also the uptake of several divalent metal cations, including Zn (Fig. 3) (Barberon et al., 2011,Fukao et al., 2011 and Shanmugam et al., 2011). This was also demonstrated in rice plants overexpressing OsIRT1, which accumulate elevated levels of $\mathrm{Zn}$ in the shoots, roots and mature seeds (Lee and An, 2009). Like their close homologue AtIRT1, AtIRT2 and AtIRT3 are also able to transport Zn into roots (Lin et al., 2009 and Vert et al., 2009). Other ZIP transporters are involved in the uptake of $\mathrm{Zn}$ from soil. For example, OsZIP1 and OsZIP3 are likely to play a role in this process (Bashir et al., 2012). In Arabidopsis, AtZIP4 expression is induced upon $Z n$ deficiency, showing its function as a $\mathrm{Zn}$ transporter (Assunção et al., 2010). The rice plasma membrane-localized OsZIP8 also seems to be a $\mathrm{Zn}$ transporter that functions in Zn uptake (Lee et al., 2010). A member of the NRAMP family, AtNRAMP1, is also able to mediate $\mathrm{Zn}$ influx into the root cells of Arabidopsis (Cailliatte et al., 2010). Zinc is also taken up from the rhizosphere in the form of Zn-PS complexes by members of the YS and YSL family (Murata et al., 2008 and Araki et al., 2011).

\section{Beneficial elements}

Since soil salinity is a global environmental challenge and $\mathrm{NaCl}$ is typically the major salt that contributes to that salinity, much research activity has been dedicated to the characterization of $\mathrm{Na}$ transport and distribution in plants, particularly to its uptake by plant roots (Zhang et al., 2010). Sodium can enter the root cells by NSCCs, more specifically by the VI-NSCCs. In fact, VI-NSCC permeability to $\mathrm{Na}$ has been demonstrated in several tissues and species, resulting in substantial evidence that root $\mathrm{Na}$ influx is mediated by these channels (Demidchik and Maathuis, 2007). Another candidate for mediating $\mathrm{Na}$ influx is the low-affinity cation transporter (LCT) 1. However, this function is still not clear and further investigation must be carried out (Amtmann et al., 2001). K and $\mathrm{Na}$ ions compete with each other to enter plant cells due to their physicochemical similarity. Therefore, it is plausible that $\mathrm{K}$ transporters may 
also be involved in $\mathrm{Na}$ acquisition and distribution. However, the involvement of $\mathrm{K}$ transporters from both the HAK/KT/KUP and AKT families in Na movement is somewhat contradictory. Some studies support the idea that some members of the HAK/KT/KUP and AKT families are involved in Na accumulation (Ardie et al., 2010, Horie et al., 2011 and Zhang et al., 2013) but others fail to confer a specific role to these transporters in $\mathrm{Na}$ influx (Nieves-Cordones et al., 2010). Significant evidence exists for the involvement of $\mathrm{K}$ transporters from the HKT families in the $\mathrm{Na}$ influx (Benito et al., 2014). The HKT family can be divided in two different sub-families according to their properties regarding $\mathrm{Na}$ and $\mathrm{K}$ transport in heterologous expression systems. Sub-family 1 , which shows Naspecific transport activity and mediates $\mathrm{Na}$ uptake, includes, among others, AtHKT1;1 and its orthologues OsHKT1;1 and HvHKT1;1 expressed in rice and barley, respectively (Haro et al., 2005, Sunarpi et al., 2005, Davenport et al., 2007 and Jabnoune et al., 2009). Sub-family 2 functions as a K-Na cotransporter and includes, among others, HvHKT2;1, OsHKT2;1, OsHKT2;2 and OsHKT2;4 (Yao et al., 2010, Mian et al., 2011 and Sassi et al., 2012). It should be noted that the involvement of a certain transporter may be genotype-specific and not transversal to all plant species.

The mechanisms of Co uptake remain poorly understood, although some transporters have been identified. Cobalt can be taken up in its ionic form $\mathrm{Co}^{2+}$ through the plasma membrane-localized AtIRT1 (Vert et al., 2002) and in the form of Co-PS complex by the ZmYS1 in maize (Murata et al., 2008). However, other membrane transporter, AtNRAMP1, shows broad selectivity for divalent cations and can also participate in the influx of Co into root cells (Cailliatte et al., 2010).

\section{Root compartmentation}

Once inside plant root cells, cations can be stored in vacuoles, transformed and/or translocated to shoot tissues. Evidence suggests that monovalent cations have a crucial role in the osmotic potential of cells. By contrast, divalent cations, like $\mathrm{Ca}^{2+}$, are usually complexed with organic compounds within cells and thus, are responsible for other tasks inside plant tissues (Martinoia et al., 2012). Plants have developed effective mechanisms to perform the chelation and sequestration of cations, such as induction of higher levels of chelating species, compartmentation in vacuoles and adsorption to the cell wall (Fig. 4). Nicotianamine (NA), glutathione (GSH), phytochelatins (PCs), metallothioneins (MTs), and organic acids have been increasingly shown in the literature to play a key role in the chelation and sequestration of several cations (Guo et al., 
2008, Larbi et al., 2010,Pal and Rai, 2010, Deinlein et al., 2012 and Haydon et al., 2012).

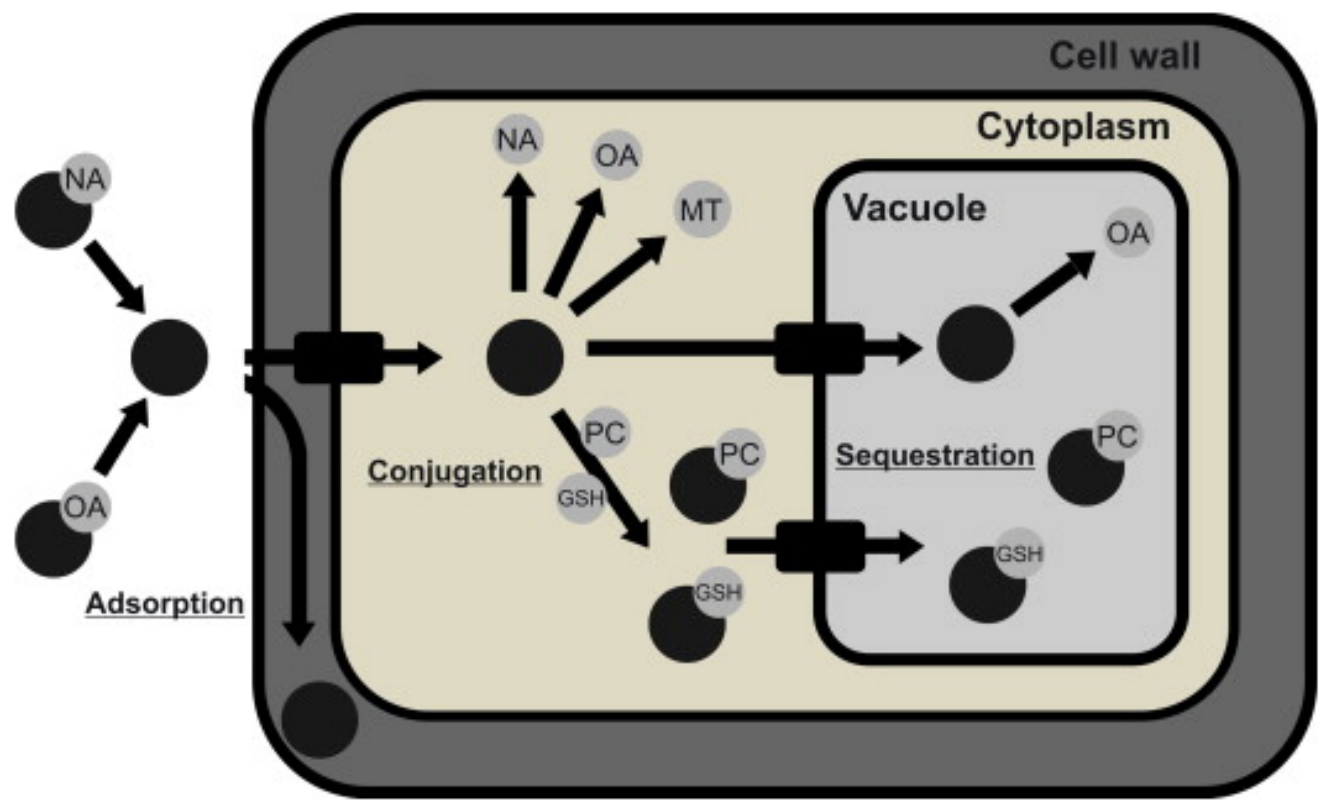

Fig. 4 .

Tolerance mechanisms for cations in plant cells. Detoxific ation usually involves conjugation followed by active sequestration in the vacuole and apoplast, where the toxic cations $c$ an be less harmful. Chelators shown are GSH: glutathione, MT: metallothioneins, NA: nic otianamine, OA: organic acids, PC: phytochelatins. Active transporters are shown as black boxes with arrows.

With respect to root compartmentation, cations may be stored in the vacuole and/or cell wall. The vacuole is generally considered to be the main storage site for cations in plant cells and vacuolar compartmentation of elements is also a part of the tolerance mechanism (Martinoia et al., 2012). However, cell wall proteins and pectins are also involved in metal chelation and tolerance (Larras et al., 2013).

\section{Macroelements}

In addition to its role in the maintenance of cell osmoticum, $\mathrm{K}$ is also required in several biochemical reactions. Since $\mathrm{K}$ is less chaotropic than $\mathrm{Na}, \mathrm{K}$ is preferentially accumulated in plant cells (Wang and Wu, 2013). Once in the cytosol, $\mathrm{K}$ can cross the tonoplast through transporters or channels. Despite the limited knowledge of the mechanisms that regulate $\mathrm{K}$ movement across the tonoplast, evidence suggests that transporters are responsible for the influx of $\mathrm{K}$ into vacuoles while channels mainly mediate its efflux to the cytosol (Martinoia et al., 2012 and Ahmad and Maathuis, 2014). The $\mathrm{Na}^{+} / \mathrm{H}^{+}$antiporters (NHX) are a class of transporters that catalyzes the electroneutral exchange of $\mathrm{Na}$ and/or 
$\mathrm{K}$ for $\mathrm{H}^{+}$by using the electrochemical $\mathrm{H}^{+}$gradient produced by the $\mathrm{H}^{+}$-ATPases present in the plasma membrane of cell organelles (Ahmad and Maathuis, 2014 and Pottosin and Dobrovinskaya, 2014). In A. thaliana, six intracellular $\mathrm{NHX}$ members are identified and divided into two groups, vacuolar (NHX1 to $\mathrm{NHX} 4$ ) and endosomal (NHX5 and NHX6) (Bassil et al., 2011). From the four vacuolar NHX transporters, two (NHX1 and NHX2) have been fully characterized and have a crucial role in the regulation of intra-vacuolar $\mathrm{K}$ in root cells (Barragan et al., 2012). Regarding K efflux to the cytosol, two families of Kpermeable channels, TPC1 (two-pore channel1) and the TPK/KCOs (two-pore $\mathrm{K}$ channels), have been identified in the tonoplast of root cells (Martinoia et al., 2012). The first class of $K$ channels is the TPC1 which was the first vacuolar channel to be identified and mediates the Ca-dependent $\mathrm{K}, \mathrm{Na}$ and $\mathrm{Mg}$ efflux from the vacuole (Hedrich and Marten, 2011). It has been suggested a possible role of TPC1 in Ca efflux from the vacuoles but some contradictory data about this issue exist in the literature (Ranf et al., 2008). The TPK/KCO family constitutes the second class of $\mathrm{K}$ channels located in the vacuolar membrane. In A. thaliana, the AtTPK/KCO family comprises five two-pore $\mathrm{K}$ channels (TPKs) and one Kir-type K channels (KCO). From the five TPKs, four (AtTPK1, $2,-3$, and -5 ) are localized in the tonoplast as well as the AtKCO3 (Voelker et al., 2010). Characterization of Arabidopsistpk1 knockout mutants and TPK1overexpressing lines demonstrate that TPK1 has an essential role in intracellular $\mathrm{K}$ homeostasis by controlling the $\mathrm{K}$ vacuolar release (Hamamoto and Uozumi, 2014).

Calcium is usually present at high concentrations in the cytosol of root cells, where it has a pivotal role in the stabilization of cell walls, and also in the vacuole, where its content is regulated by a larger number of $\mathrm{Ca}$ transporters (Pittman, 2011). The cytosolic concentration of $\mathrm{Ca}$ is around $100 \mathrm{nM}$ while the vacuolar concentration is in the $\mathrm{mM}$ range. Hence, vacuolar compartmentation of $\mathrm{Ca}$ is an energy-dependent process mediated by two classes of $\mathrm{Ca}$ vacuolar transporters (Martinoia et al., 2012). The first class includes the P-type CaATPases and includes two Ca transporters, ACA4 and ACA11, localized in the vacuolar membrane. ACA4 occurs mainly on small vacuoles, whereas ACA11 is localized in the large vacuoles of root cells (Lee et al., 2007). The second class of vacuolar $\mathrm{Ca}$ transporters includes the $\mathrm{Ca}^{2+} / \mathrm{H}^{+}$exchangers (CAXs). Six CAX transporters have been identified in $A$. thaliana that are split into two phylogenetic groups that seems to reflect their functional variation (Manohar et al., 2011). The Type-1B group, which includes CAX2, CAX5 and CAX6, seem to have a broader substrate specificity confirmed by its ability to transport several divalent cations (e.g., Mn and Cd) besides Ca (Edmond et al., 2009). The Type 
$1 \mathrm{~A}$ group, including the CAX1, CAX3 and CAX4 transporters, appears to have a higher specificity for Ca transport (Cheng et al., 2005).

Arabidopsis cax1 knockout mutants do not suffer significant changes in their $\mathrm{Ca}$ content, however, cax1cax3 double mutants exhibited reduced $\mathrm{Ca}$ concentration in their vacuoles compared to wild-type plants ( Conn et al., 2011b and Connorton et al., 2012).

Plants growing on Mg-rich soils use this divalent cation as an osmotic regulator. The MGTs (Mg transporters) are the major transporters of this cation described in plants. In $A$. thaliana, 10 members with $\mathrm{Mg}^{2+} / \mathrm{H}^{+}$antiport activity are identified (Martinoia et al., 2012). Two of them, AtMGT2/AtMRS2-1 and AtMGT3/AtMRS2-5, are localized in the vacuolar membrane. Plant lines overexpressing these transporters have shown $\mathrm{Mg}$ accumulation (Conn et al., 2011a). Arabidopsis $\mathrm{Mg}^{2+} / \mathrm{H}^{+}$exchanger (AtMHX) is another putative vacuolar $\mathrm{Mg}^{2+} / \mathrm{H}^{+}$antiporter that seems to mediate the $\mathrm{Mg}$ influx across the tonoplast (Shaul et al., 1999). The same mechanism was also observed in the hyperaccumulatorArabidopsis halleri expressing an AtMHX homolog ( Elbaz et al., 2006).

\section{Trace essential elements}

Plants require certain micronutrients for proper growth and development. For example, $\mathrm{Fe}$ is involved in numerous redox reactions, $\mathrm{Cu}$ has a crucial role in electron transfer between photosystem I and II, $\mathrm{Mn}$ is required as a cofactor for a variety of enzymes, such as the Mn-dependent superoxide dismutase (MnSOD), and $\mathrm{Zn}$ acts as a catalytic or structural co-factor in a large number of enzymes and regulatory proteins (Hänsch and Mendel, 2009). Micronutrients deficiency is a more common reality that toxicity. Hence, plants usually accumulate extra nutrients to sustain their growth in times of need. To accomplish that, micronutrients are translocated to seeds where they can support the growth of new plantlet. Therefore, most of these micronutrients are not retained in plant roots, so this topic is less relevant to discuss. Only a brief overview will be made here.

The bulk of Fe is found in leaves chloroplasts, where this element is engaged in several biochemical reactions (Hänsch and Mendel, 2009). A certain amount of this micronutrient can also be stored in the leaves vacuoles or mitochondria (Martinoia et al., 2012). Iron can also be stored in seeds vacuoles (Kim et al., 2006b). Its storage in root cells is not very common.

Non-tolerant plant species, such as $A$. thaliana, can use chelation as a mechanism to avoid Cu-induced damage in the root cells. In a Cu-rich environment, MTs and PCs are usually up-regulated in response to Cu stress 
( Guo et al., 2008 and Pal and Rai, 2010). Four Arabidopsis MTs (AtMT1a, AtMT2a, AtMT2b, and AtMT3) have been implicated in the $\mathrm{Cu}$ accumulation and tolerance in roots under high $\mathrm{Cu}$ levels (Guo et al., 2008). In addition to the MTs tolerance mechanism, $\mathrm{Cu}$ can be sequestered in the vacuole. A member of the HMA (Heavy Metal Associated) family, AtHMA5, mediates the vacuolar $\mathrm{Cu}$ influx in Arabidopsis root cells (Andres-Colas et al., 2006). In A. thaliana, one of the six COPTs identified is targeted to the tonoplast. An

Arabidopsis copt5 knockout mutant exhibits severe defects in vegetative growth and root elongation, accumulating more $\mathrm{Cu}$ in the roots and translocating less $\mathrm{Cu}$ to the shoots. These results support the fact that AtCOPT5 would act as a vacuolar Cu exporter ( Garcia-Molina et al., 2011 and Klaumann et al., 2011). A large pool of $\mathrm{Mn}$ (around $80 \%$ ) is usually observed in leaf vacuoles. Moreover, a significant accumulation of $\mathrm{Mn}$ is also present in leaf chloroplasts where this element is required as the catalytic center for light-induced water oxidation in photosystem II (Pittman, 2005). The previously mentioned AtCAX2 and AtCAX4 transporters that are engaged in the transport of Ca have also the ability to transport $\mathrm{Mn}$ into the vacuole (Edmond et al., 2009 and Connorton et al., 2012). AtMTP11, which belongs to the cation diffusion facilitator (CDF) family, is implicated in the pre-vacuolar compartmentation of $\mathrm{Mn}$ in root cells (Delhaize et al., 2007). In Arabidopsis, the export of Mn from vacuoles can be performed by AtNRAMP3 and AtNRAMP4 which were shown to have a crucial role in the Mn homeostasis within plant tissues (Lanquar et al., 2010). The Ptype ATPase AtECA3, mainly expressed in root tissues, participates in the influx of $\mathrm{Mn}$ into the Golgi complex (Mills et al., 2008).

After uptake into the root symplast, Ni detoxification at the cellular level is achieved by transport of $\mathrm{Ni}$, as a free ion or chelated with appropriate ligands, to the storage sites such as the vacuole and cell wall (Bhatia et al., 2005). A recent study showed that the main mechanism that confers Ni tolerance seems to be vacuolar Ni sequestration (Saito et al., 2010). A member of the IREG/FPN (Iron-Regulated/Ferroportin) family, AtIREG2/FPN2, has been identified in the tonoplast of root cells and mediates vacuolar Ni loading (Schaaf et al., 2006). Once in the root symplast, $\mathrm{Zn}$ can be immobilized in the root through transport into vacuoles. Evidence suggests that the speciation of $\mathrm{Zn}$ in the root symplast has a direct influence in the extent of $\mathrm{Zn}$ immobilization in root vacuoles (Sinclair and Kramer, 2012). The vacuolar membrane transporter AtMTP1 has an essential role in detoxification of excessive $\mathrm{Zn}$. When grown in a $\mathrm{Zn}$-rich medium, the mutant line of Arabidopsis that lacks MTP1 was not able to accumulate $\mathrm{Zn}$ in vacuoles, unlike wild-type roots (Kawachi et al., 2009). The tonoplast-localized AtMTP3 also contributes to basic cellular Zn tolerance and 
controls $\mathrm{Zn}$ partitioning. Overexpression of MTP3 increases $\mathrm{Zn}$ accumulation in roots of $A$. thaliana ( Arrivault et al., 2006). The P1B-type ATPase subfamily HMA plays a key role in the process of metal allocation or detoxification in plants. At least eight (HMA1-HMA8) members are identified in A. thaliana. AtHMA1 to AtHMA4 belong to the group implicated in divalent cation transport whereas AtHMA5 to AtHMA8 act on monovalent Cu ion transport ( Zorrig et al., 2011). From the four HMAs involved in divalent cations transport, one of them, AtHMA3, seems to play a role in the detoxification of $\mathrm{Zn}$ by participating in its vacuolar sequestration in root cells (Morel et al., 2009). It has been speculated that ZIF1 (for Zinc-Induced Facilitator1) is involved in a mechanism of vacuolar $\mathrm{Zn}$ sequestration. Specifically, AtZIF1 has been implicated in the transport of $\mathrm{Zn}$ complexes (mainly with NA) into the vacuole, since overexpression of ZIF1 leads to strongly enhanced retention of $Z n$ in root vacuoles (Haydon et al., 2012). A member of the ZIP family, AtZIP1, may contribute to the remobilization of $\mathrm{Zn}$ from the vacuole to the cytoplasm in Arabidopsis roots (Milner et al., 2013). Moreover, the tonoplast-localized NRAMP4 also seems to mediate the vacuolar $\mathrm{Zn}$ export in root cells (Oomen et al., 2009).

\section{Beneficial elements}

Sodium is a ubiquitous cation present in all soils. Soils can contain high concentrations of $\mathrm{Na}$, which can be readily absorbed by most plants. Since high $\mathrm{Na}$ concentrations within the cytosol can be toxic, vacuolar Na storage is essential for plants to survive under high salinity conditions (Martinoia et al., 2012 and Benito et al., 2014). As already described, the NHX family is a $\mathrm{Na}^{+} / \mathrm{H}^{+}$antiporter. Several member of the $\mathrm{NHX}$ family (NHX1-4) are targeted in the vacuole and are known to be involved in salt tolerance. Furthermore, the endosomal-localized NHX5 and NHX6 also seem to be engaged in this process, suggesting a complex interactive coordination between different cell organelles in response to salinity (Krebs et al., 2010 and Bassil et al., 2011).

As regard to Co, few studies have addressed its compartmentation. In fact, the only evidence about vacuolar compartmentation of Co comes from the study of Morrissey et al. (2009) who found that AtIREG2/FPN2, besides being involved in the vacuolar sequestration of $\mathrm{Ni}$, also seems to mediate Co transport across the tonoplast in root cells.

\section{Translocation}

Translocation in plants involves a series of steps, as follows: (1) radial transport across the root tissues, which include symplastic transport to pass through the Casparian strip (a waxy coating that prevents solutes from entering the root 
xylem directly from the soil solution or root apoplast); (2) xylem loading, transport and unloading; (3) xylem-to-phloem transfer; (4) phloem loading, transport and unloading; (5) symplastic movement toward the site of demand; and (6) retranslocation from source or senescing tissue (Kobayashi and Nishizawa, 2012).

Although some transporters are highly specialized in the movement of a certain cation, others show low substrate specificity and can translocate different elements (Zorrig et al., 2011). Some cations are chelated by organic acids, which are involved in metal absorption by plant roots, translocation in the xylem and storage in the leaf cells vacuoles (Karley and White, 2009 and Larbi et al., 2010). Cations can also be bound by NA and mobilized by the YSL family transporters (Aoyama et al., 2009, Ishimaru et al., 2010 and Harris et al., 2012). It should be emphasized that cation translocation is a complex process involving multiple networks. Specialized proteins can transport elements with similar characteristics (e.g., oxidative state), inducing competition that can results in deficiency, toxicity and/or accumulation in the above-ground plant tissues (Puig and Penarrubia, 2009).

\section{Macroelements}

A large fraction of the $\mathrm{K}$ taken up by plant roots is translocated to the shoot. Potassium is transported symplastically to the xylem, where the Shaker-like channel AtSKOR, expressed in the root pericycle and stelar parenchyma of Arabidopsis, is thought to be involved in $\mathrm{K}$ loading of the xylem (Johansson et al., 2006). The loading of $K$ within the shoot is mainly determined by transpirational water flows and the shoot apoplastic K concentration (Ahmad and Maathuis, 2014). In addition to the transport of $K$ into above-ground tissues, a large shoot-to-root $\mathrm{K}$ flux through the phloem is maintained. In Arabidopsis, the redistribution of $K$ from leaves to phloem-fed tissues seems to be mediated by the Shaker-like channel AtAKT2/AKT3, which is mainly expressed in the phloem and xylem parenchyma and has been indicated to be involved in phloem loading and unloading (Gajdanowicz et al., 2011).

Calcium is relatively immobile within plant tissues and thus, it is likely that most of the $\mathrm{Ca}$ is sequestered in the root cells vacuoles (Maathuis, 2009). Until now, no transporters have been identified to be responsible for $\mathrm{Ca}$ xylem loading, although it is possible for $\mathrm{Ca}$ to be symplastically transported across the root to the xylem (Karley and White, 2009). Evidence suggests that Ca reaches the xylem apoplastically through regions of the root where the Casparian strips are absent or via the cytosol of unsuberised endodermal cells where Casparian strips are present (Baxter et al., 2009). This assumptions support the 
observation that Ca mobilization to the shoot occurs mainly from the root apex and/or regions of lateral root initiation, where the Casparian strip is disrupted (Shaul, 2002 and White et al., 2002). Once in the vascular system, Ca mobility is also low. Calcium is transported in the xylem as free ions $\left(\mathrm{Ca}^{2+}\right)$ or complexed with organic acids (Karley and White, 2009). Additionally, it seems that the rhizosphere $\mathrm{Ca}$ concentration has an important effect on the $\mathrm{Ca}$ concentration in the xylem sap and transpirational water flows governs Ca delivery within the shoot (White et al., 2002).

Magnesium is loaded into the xylem sap, where it is present as free ions $\left(\mathrm{Mg}^{2+}\right)$ or complexed with organic acids (Karley and White, 2009). To date, little information is available regarding membrane transporters engaged in the $\mathrm{Mg}$ xylem loading. Recently, it was suggested that members of the MRS2/MGT family could be involved in the Mg transport system (Tanoi et al., 2011), but the exact transporter has not been identified yet. As for $\mathrm{Ca}$, evidence suggests that, besides the symplastic pathway, Mg can be loaded into the xylem vessels apoplastically and it seems that this pathways is the preferred for xylem $\mathrm{Mg}$ loading (Shaul, 2002).

\section{Trace essential elements}

Within plant tissues, Fe has low solubility and high reactivity thus its movement along the plant tissues must be associated with appropriate chelating compounds and proper control of redox states (Kobayashi and Nishizawa, 2012). Several lines of evidence have indicated that the main Fe chelators are citrate (Rellan-Alvarez et al., 2010 and Harris et al., 2012), NA (Ishimaru et al., 2010) and MAs (Aoyama et al., 2009 and Kakei et al., 2012). Citrate has been proved to play a key role in the Fe chelation and mobilization in xylem sap. To facilitate the efflux of citrate into the xylem, Arabidopsis relies on the FRD3 (Ferric Reductase Defective 3) transporter which is expressed in the root pericycle cells (Fig. 5) (Durrett et al., 2007). In rice, an AtFDR3 orthologue, OsFRDL1, is also expressed in root pericycle cells and encodes a citrate effluxer required to load citrate into the xylem sap (Yokosho et al., 2009). OsPEZ1 and OsPEZ2 are also responsible for xylem loading of phenolics enhancing the remobilization of Fe along the plant body (Bashir et al., 2011a and Ishimaru et al., 2011). Although AtFRD3, OsFRDL1, OsPEZ1 and OsPEZ2 can efflux the Fe-chelating molecules, Fe must also be transported into the xylem. To date, the plasma membrane-localized IREG1/FPN1 present in Arabidopsis stele, is the only Fe effluxer identified to mediate the vascular loading of Fe (Morrissey et al., 2009). Among the influx transporters, members of the YS and YSL transporters are widely involved in Fe translocation. In barley 
and maize, the YS1 transporter is able to mobilize Fe-PS complexes (Murata et al., 2008 and Ueno et al., 2009). Among the 18 YSL transporters present in rice, OsYSL2, OsYSL15, OsYSL16, OsYSL18 were identified as Fe-PS transporters involved in the Fe translocation. More specifically, OsYSL2 is proved to be a Fe-NA transporter, whereas OsYSL15, OsYSL16, OsYSL18 translocate Fedeoxymugineic acid (DMA) complexes (Aoyama et al., 2009, Inoue et al., 2009, Ishimaru et al., 2010 and Kakei et al., 2012). The efflux of NA in rice was found to be facilitated by the ENA1 (efflux transporter of nicotianamine 1) and ENA2, and the efflux of MA is achieved by TOM1 (Nozoye et al., 2011). Members of the YSL family are also present in non-graminaceous plants that do not synthesize MAs. It is widely assumed that non-graminaceous plants rely on the YSL transporters to translocate Fe-NA complexes. NA is a precursor and structural analog of MAs; it has the ability to chelate Fe and other metals and is synthesized by all plants, in contrast to the graminaceous-specific synthesis of MAs. The Arabidopsis YSL members AtYSL1, AtYSL2 and AtYSL3 were identified to have a key role in the mobilization of $\mathrm{Fe}$ inside the plant (Chu et al., 2010). Besides their presence in the outer root cells, some FRO genes can also be expressed in root or shoot vascular cells (Jeong and Connolly, 2009), suggesting that $\mathrm{Fe}$ reduction can occur within plant tissues with further $\mathrm{Fe}$ translocation by members of the IRT and/or NRAMP families (Takahashi et al., 2011). The oligopeptide transporters (OPT) seem to play an important role in the mobilization of Fe. OPT3 was markedly expressed in aerial parts of both $A$. thaliana and Thlaspi caerulescens, including stem and leaf, suggesting that this transporter may be involved in the long-distance Fe transportation ( Stacey et al., 2008 and Hu et al., 2012). 


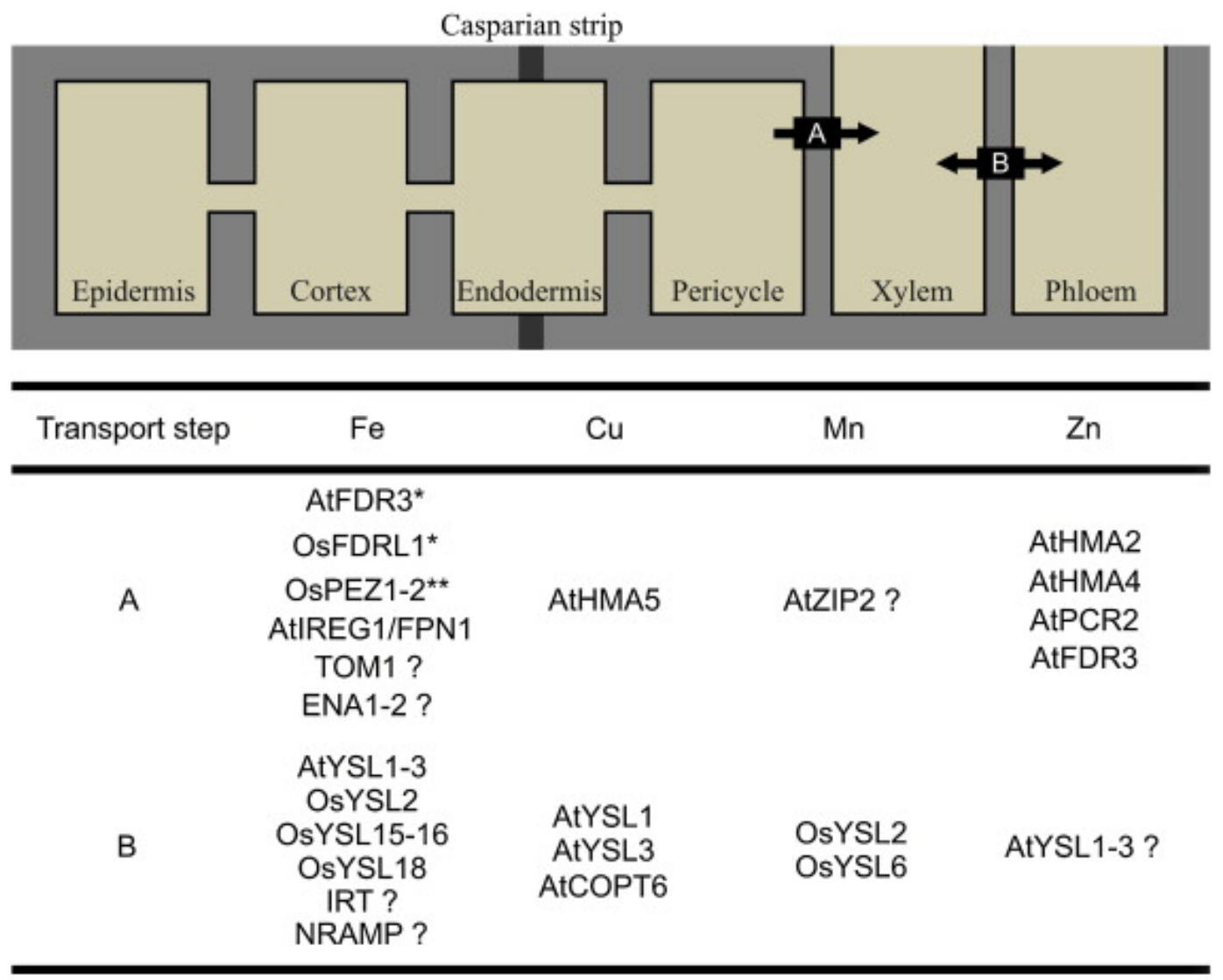

Fig. 5 .

Schematic illustration of some of the key transport steps for the transloc ation of $\mathrm{Fe}, \mathrm{Cu} \mathrm{Mn}$ and $\mathrm{Zn}$ in the plant (Arabidopsis thaliana and Oryza sativa were used as model plants). The proteins identified for mediating some of these transport functions are given in the table below. The arrows indic ate the direction of transport and each letter in the figure corresponds to the list given in the first column of the table.

In order to be translocated, Cu must be exported from the root symplast before entering the xylem. Evidence suggests that the export from the root symplast is mediated by an HMA family transporter. In Arabidopsis, AtHMA5 is highly expressed in roots, flowers and pollen and seems to be responsible for root $\mathrm{Cu}$ detoxification (Andres-Colas et al., 2006). This phenotype function is the opposite of COPT, corroborating the idea that AtCOPT1 and AtHMA5 transport $\mathrm{Cu}$ in opposite directions (Fig. 5) (del Pozo et al., 2010). Cu translocation may involve chelators such as NA and several amino acids (Irtelli et al., 2009 and Harris et al., 2012). Moreover, $\mathrm{Cu}$ in the xylem sap of rice seems to be bound to DMA, while in the phloem sap, Cu mainly complexes with NA and histidine (Ando et al., 2013). OsYSL16 is a Cu-NA transporter required for delivering $\mathrm{Cu}$ to developing young tissues and seeds through phloem transport (Zheng et al., 2012). In Arabidopsis root, the plasma membrane-localized AtYSL1 and AtYSL3 were proven to be involved in the root-to-shoot $\mathrm{Cu}$ transport (Waters and Grusak, 2008 and Chu et al., 2010). In Arabidopsis, 
AtCOPT6 is expressed in different cell types of different plant compartments, but the bulk of its expression is located in the vasculature suggesting a role in Cu translocation (Jung et al., 2012). Similarly, OsCOPT6 is not expressed in root but is highly expressed in leaf, stem and sheath (Yuan et al., 2011). Furthermore, the oligopeptide transporter AtOPT3 and its orthologue TcOPT3 seem to participate in the mobilization of $\mathrm{Cu}$ (Stacey et al., 2008 and Hu et al., 2012).

The translocation of $\mathrm{Mn}$ involves chelators such as NA, amino acids and carboxylic acids (Harris et al., 2012). In Arabidopsis, AtZIP2 seems to participate in $\mathrm{Mn}$ transport into the root vasculature for translocation to the shoot (Fig. 5) (Milner et al., 2013). In rice, OsYSL6 is a Mn-NA transporter that is required for the detoxification of excess $\mathrm{Mn}$ (Sasaki et al., 2011). Likewise, OsYSL2 is involved in Mn translocation in the phloem. In the knockout ys/2 line, rice seeds and shoots contain lower Mn content compared with the wild-type (Ishimaru et al., 2010). Moreover, the same transporter (YSL2) shows the ability to transport Mn-PS complexes in barley roots (Araki et al., 2011). The oligopeptide transporter AtOPT3 seems to play an important role in the longdistance Mn transport (Stacey et al., 2008).

Nickel is translocated from roots to shoots as a free ion $\left(\mathrm{Ni}^{2+}\right)$ and complexed with several molecules such as histidine and citrate (Richau et al., 2009 and Centofanti et al., 2013). In hyperaccumulator plants, Ni was shown to be translocated also in the form of Ni-NA complexes (Mari et al., 2006). The transport of NA-metal chelates, required for the xylem loading and unloading, has been assigned to the YSL family. In $T$. caerulescens, two YSL genes, TcYSL5 and TcYSL7 were found to be expressed around the vasculature of the shoots and in the central cylinder of the roots, suggesting that YSL transporters play a key role in the translocation of Ni-NA complexes ( Gendre et al., 2007). Zinc is exported from root by two members of the P-type ATPase family, HMA2 (expressed in Arabidopsis, rice and barley) and HMA4 (Fig. 5) (Mills et al., 2012 and Takahashi et al., 2012b). However, other transporters can also perform the export of $\mathrm{Zn}$ to vascular tissues. In Arabidopsis, pcr2 knockout mutants accumulate $Z n$ in roots, suggesting a role of AtPCR2 in the root-toshoot $\mathrm{Zn}$ translocation ( Song et al., 2010). Furthermore, it was proved that AtFRD3 is involved in loading $Z n$ into xylem (Pineau et al., 2012). $Z n$ can also be exported from the roots in the form of $\mathrm{Zn}$ complexes. Before being exported, Zn must be mobilized to pericycle cells, apparently by HvYSL2 (Araki et al., 2011). After xylem loading, $\mathrm{Zn}$ can be transported to above-ground tissues by the YS and YSL transporters. There is some evidence that AtYSL1, AtYSL2 and AtYSL3 are involved in the transport of Zn (Chu et al., 2010). 
Phytosiderophores such as NA and DMA are important in the distribution of Zn within the plant ( Suzuki et al., 2008,Harris et al., 2012 and Nishiyama et al., 2012). Although no Zn-PS transporters have been identified yet, the presence of these complexes in the xylem and phloem sap suggests that members of the YSL family may be involved in the transport of Zn complexes ( Rellan-Alvarez et al., 2008 and Deinlein et al., 2012). Moreover, members of the ZIP family are expressed in the vascular bundle, suggesting that they contribute to the distribution of $\mathrm{Zn}$ along the plant (Bashir et al., 2012). AtOPT3 and its orthologue TcOPT3 seem to participate in the long-distance transport of $\mathrm{Zn}$ ( Stacey et al., 2008 and Hu et al., 2012).

\section{Beneficial elements}

The export of $\mathrm{Na}$ to the xylem is assumed to be an active process. In Arabidopsis, SOS1 was proposed to be involved in the loading of $\mathrm{Na}$ into the xylem (Shi et al., 2002). However, at the whole-plant level, the specific role of AtSOS1 still remains uncertain (Kronzucker and Britto, 2011). At high Na levels, xylem loading with $\mathrm{Na}$ is thought to occur passively through channels, since a higher cytosolic $\mathrm{Na}$ content in xylem parenchyma cells and a relatively depolarized plasma membrane would promote the movement of $\mathrm{Na}$ into the xylem sap (Apse and Blumwald, 2007). Several lines of evidence exist supporting the role of AtHKT1;1 and its orthologue OsHKT1;5 in xylem unloading (Sunarpi et al., 2005 and Davenport et al., 2007). A demonstration of $\mathrm{Na}$ efflux from shoot xylem vessels was achieved by overexpressing AtHKT1;1 in the mature root stele of $A$. thaliana, which showed decreased $\mathrm{Na}$ accumulation in the shoot ( Moller et al., 2009).

For Co, little evidence is available regarding its translocation. However, an Arabidopsisfpn1 knockout mutant showed low Co accumulation in shoot tissues, indicating that ferroportins play an important role in Co homeostasis, more specifically in the root-to-shoot Co translocation ( Morrissey et al., 2009).

\section{Leaves compartmentation}

The transport of inorganics into leaf cells from leaf xylem involves another membrane transport step mediated by specific membrane transport proteins. Once inside the leaf symplast, cations can be assimilated in the cytosol or stored in cellular organelles. The general rule is that nutrients are assimilated, playing a key role in several physiological mechanisms, and toxic elements are stored in places where they cause the least harm to cellular processes. However, it should be noted that nutrients can also be stored for two reasons: (i) they can become deficient and plant accumulates them for times of 
necessity; (ii) they are at high concentrations and can pose a toxicity problem to plants (Maathuis, 2009, Pilon-Smits et al., 2009 and Pilon et al., 2009). At the tissue level, toxic elements are generally accumulated in the epidermis and trichomes (Tian et al., 2009 and Sanchez-Pardo et al., 2012); at the cellular level, they may be accumulated in the vacuoles or cell wall (Cosio et al., 2005). The distribution of cations in leaf tissues is generally asymmetric ( $\mathrm{Wu}$ and Becker, 2012). The accumulation of toxic cations in leaf vacuoles makes sense because vacuoles do not contain a photosynthetic apparatus, which would be sensitive to toxicity (Martinoia et al., 2012). Toxic cation storage occurs also in highly tolerant cells such as the leaf epidermis and the vein bundle sheath, as long as their import remains under control. Once the cation accumulation exceeds the tolerance threshold of the plant, they would be transported to mesophyll cells, which are more sensitive to toxic cations than other cell types, allowing photosynthesis to be threatened (Zhao et al., 2012). At present, the physiological mechanisms involved in the sequestration of cations between different leaf tissues remain only partially understood. One possible mechanism is the differential expression of cation transporters in the plasma membrane and/or tonoplast between mesophyll and other tissues (Morel et al., 2009).

\section{Macroelements}

The transport of $\mathrm{K}$ from the xylem into the leaf symplast is mediated by membrane transporters and channels. Members of the HAK/KT/KUP family were found to be highly expressed in shoot tissues. Specifically, AtKUP1, AtKUP2 and AtKUP4 were expressed in Arabidopsis leaves, suggesting an involvement in $\mathrm{K}$ xylem unloading (Wang and Wu, 2013). Moreover, Ahn et al. (2004) also showed that other AtKUPs were highly expressed in leaves. In particular, AtKUP6, AtKUP8 and AtKUP9 were highly expressed in young leaves, whereas AtKUP10 and AtKUP12 expression was evident in both older and younger leaves. Shaker channels AtKT1, AtKT2 and AtKC1 are also highly expressed in the plasma membrane of Arabidopsis leaves, indicating that these cation channels are enrolled in the movement of $\mathrm{K}$ between shoot tissues (Jeanguenin et al., 2011). Regarding the intracellular distribution of $\mathrm{K}$ in leaves, the vacuolar $\mathrm{K}$ transporters AtNHX1 and AtNHX2, expressed in the tonoplast of Arabidopsis leaf vacuoles, mediate the influx of $\mathrm{K}$ into this cell organelle (Fig. 6) (Bassil et al., 2011). To mediate the vacuolar $\mathrm{K}$ efflux, several members of the TPK/KCOs family, such as AtTPK1, AtTPK3, AtTPK5 and AtKCO3, are expressed in the vacuolar membrane of leaf vacuoles and mediate this process (Voelker et al., 2010 and Hamamoto and Uozumi, 2014). Regarding other cell organelles, a member of the $\mathrm{CHX}$ family, AtCHX23, was found to be expressed 
in the chloroplast envelope of Arabidopsis leaf cells. Analysis of Arabidopsis chx23 knockout mutant leaves suggests that $\mathrm{CHX} 23$ could mediate the co-transport of $\mathrm{K}$ across the chloroplasts envelope of leaf cells ( Song et al., 2004). Recently, a member of the $K$ efflux antiporters (KEA) has also been identified in Arabidopsis chloroplasts. AtKEA2 was found to be highly expressed in leaves and mediates $\mathrm{K}$ transport across the plastid envelope (Aranda-Sicilia et al., 2012).

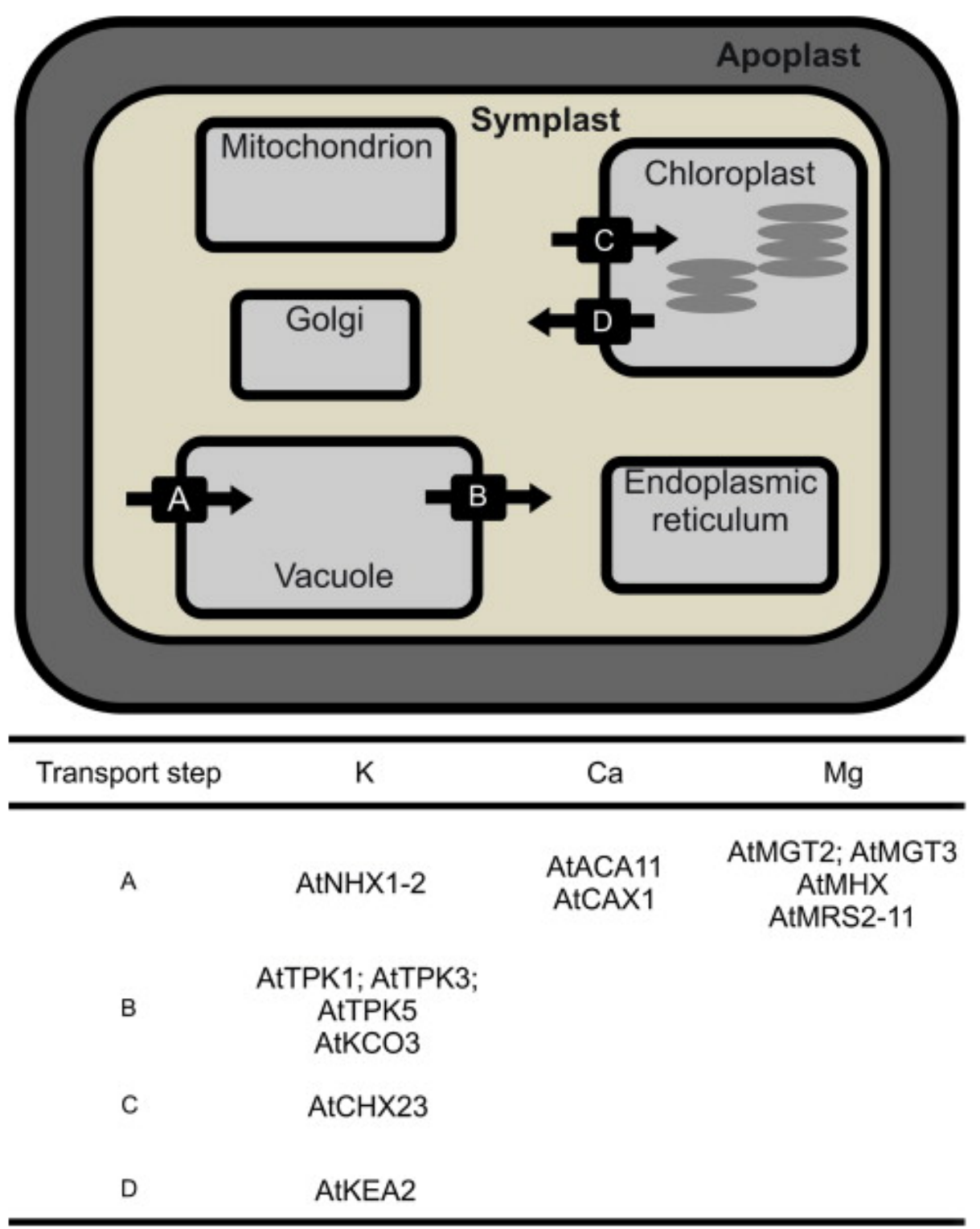

Fig. 6.

Schematic illustration of the subcellular loc alization of transporters involved in the movement of $\mathrm{K}, \mathrm{Ca}$ and Mg in Arabidopsis thaliana. Members of the AtNHX, AtTPK, AtKCO, AtCHX, AtKEA, AtACA, AtCAX, AtMGT, AtMHX and AtMRS families are targeted in intrac ellular membranes: tonoplast (AtNHX1-2, AtACA11, AtCAX1, AtMGT2, AtMGT3, AtMHX, AtMRS2-11, AtTPK1, AtTPK3, AtTPK5 and AtKCO3) and chloroplast envelope (AtCHX23 and AtKEA2). The arrows indic ate the direction of transport and each letter in the figure corresponds to the list given in the first column of the table. 
Within the leaf, Ca follows mainly the apoplastic pathway and tends to accumulate in the mesophyll cells, trichomes and epidermal cells. The cytosolic $\mathrm{Ca}$ concentration is very sensitive to the apoplastic $\mathrm{Ca}$ concentrations. Thus, $\mathrm{Ca}$ is usually stored in leaf vacuoles and/or specific cell organelles to avoid excessive apoplastic Ca accumulation (White and Broadley, 2003). However, before been sequestered in the leaf vacuoles, Ca must be transported across the plasma membrane of leaf cells. Although most members of the NSSC are present in the root cells, several lines of evidence suggest that VI-NSCCs can also be found in leaf cells (Demidchik and Maathuis, 2007). In the vacuoles of leaf cells, $\mathrm{Ca}$ is present as the ionic species $\mathrm{Ca}^{2+}$, in soluble forms (e.g., complexed with proteins and/or organic acids) and/or in insoluble forms (e.g., Ca-oxalate and Ca-phytate) (Karley and White, 2009). The transport of $\mathrm{Ca}$ across the vacuolar membrane of leaf cells is thought to be performed by members of the ACA and CAX families (Fig. 6). AtACA11 is targeted to the vacuolar membrane of Arabidopsis leaf cells and mediates Ca transport across the tonoplast of large vacuoles (Lee et al., 2007). In the CAX family, AtCAX1 is highly expressed in the vacuoles of leaf cells and has an important role in $\mathrm{Ca}$ influx into the vacuole (Cheng et al., 2005 and Conn et al., 2011b). AtCAX2, AtCAX5 and AtCAX6 were also expressed in Arabidopsis leaves, although in a lower extent than AtCAX1 (Edmond et al., 2009).

Members of the MGT/MRS2 family are thought to mediate the leaf uptake of Mg (Gebert et al., 2009 and Karley and White, 2009). It was shown that AtMGT9 is expressed in leaf cells and thus can be involved in Mg transport (Chen et al., 2009). Once in the cytosol of leaf cells, Mg can be accumulated in several cell organelles. Evidence suggests that mesophyll cells accumulate the highest vacuolar concentration of $\mathrm{Mg}$ in Arabidopsis leaves. To accomplish that, plants rely on members of the MGT/MRS2 family, such as AtMGT2/MRS2-1 and AtMGT3/MRS2-5, which are localized in the tonoplast of Arabidopsis leaf cells and mediate the Mg influx into the vacuole (Fig. 6) (Conn et al., 2011a). AtMHX is also involved in $\mathrm{Mg}$ influx across the tonoplast of leaf cells (Shaul et al., 1999 and Elbaz et al., 2006). A member of the MGT/MRS2 family, AtMRS2-11, was expressed in the chloroplast envelope and plays a key role in the $\mathrm{Mg}$ transport into this cell organelle (Drummond et al., 2006).

\section{Trace essential elements}

Fe can be transported into the leaf symplast as free ion or complexed with PS. Members of the IRT family are expressed in leaf tissues of Arabidopsis suggesting their involvement in the Fe acquisition (Lee and An, 2009, Lin et al., 2009 and Barberon et al., 2011). Regarding Fe-PS complexes, members of the 
YSL family seems to mediate the Fe influx into the cytosol of leaf cells (Kakei et al., 2012). Once in the leaf symplast, Fe must be delivered into leaf cells to participate in multiple biochemical processes. The chloroplast is the largest pool of Fe in plant cells accumulating $80-90 \%$ of cellular Fe (Kobayashi and Nishizawa, 2012). The influx of $\mathrm{Fe}$ into the chloroplast of $A$. thaliana is achieved by the PIC1 (permease in chloroplast 1) localized in the inner envelope membrane of chloroplasts ( Fig. 7) (Duy et al., 2011). AtFRO7 is localized in the chloroplast envelope and looks to be critical for chloroplast Fe acquisition (Jeong and Connolly, 2009). Mitochondria are other plant sites where $\mathrm{Fe}$ is essential. Bashir et al. (2011b) identified the rice mitochondrial Fe transporter (MIT), which is essential for rice growth and development. Moreover, AtFRO3 and AtFRO8 are localized in mitochondria membrane, which indicates that these ferric reductase oxidases must be involved in mitochondrial $\mathrm{Fe}$ homeostasis (Jeong and Connolly, 2009). The vacuole generally functions as a metal pool to avoid toxicity. The transporters OsVIT1 and OsVIT2 mediate the influx of Fe across the vacuolar membrane into the vacuole (Zhang et al., 2012). Likewise, it seems that the IREG2/FPN2 present in Arabidopsis tonoplast may play a role in the influx of Fe from the cytoplasm into the vacuole (Morrissey et al., 2009). On the other hand, both AtNRAMP3 and AtNRAMP4 export Fe from vacuoles (Lanquar et al., 2005). In the Golgi complex, the MATE (multidrug and toxic compound extrusion) transporter BCD1 has a role in sustaining Fe homoeostasis by reallocating excess Fe released from stressinduced cellular damage in Arabidopsis (Seo et al., 2012). 


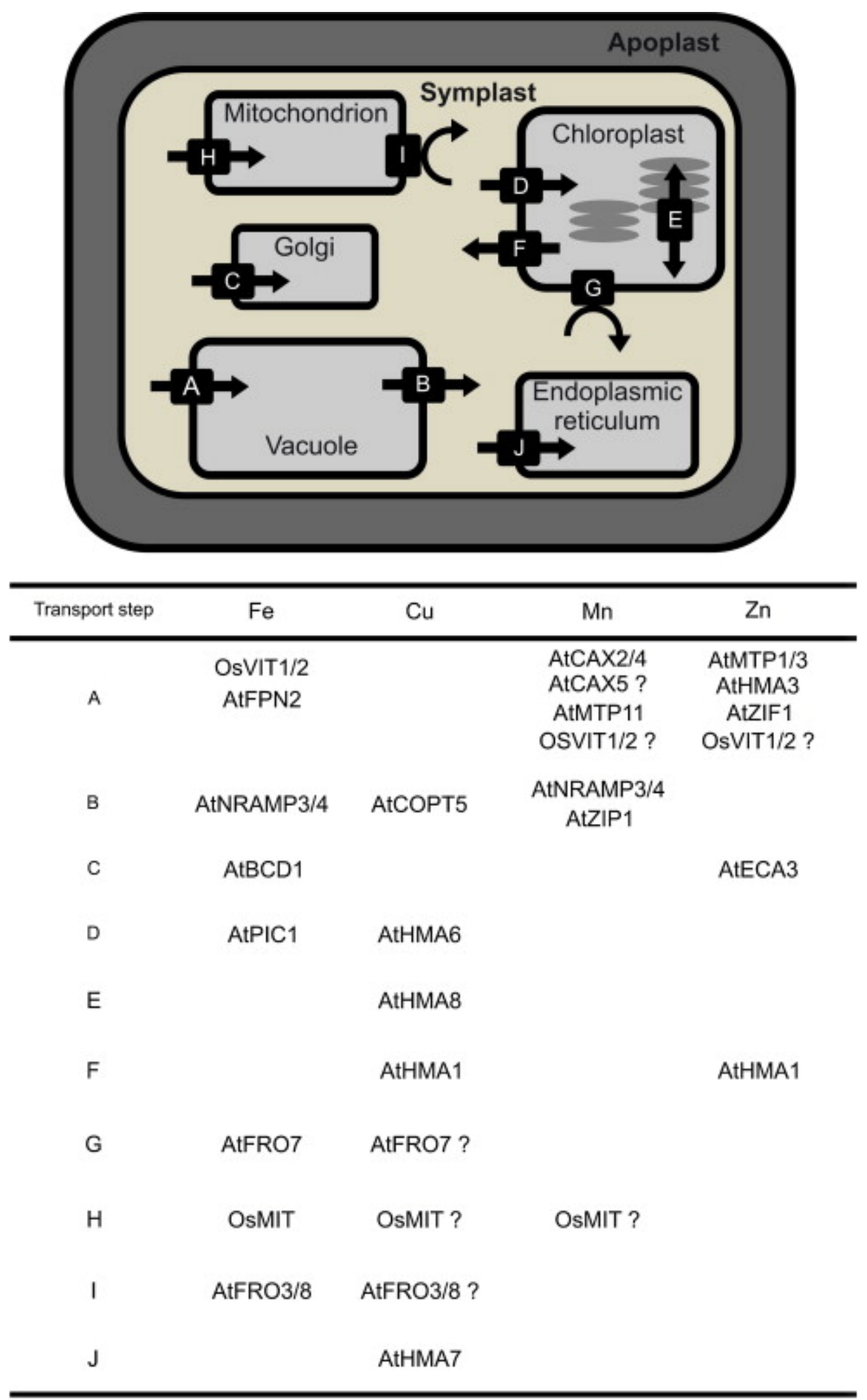


Fig. 7 .

Schematic illustration of the subcellular loc alization of transporters and reductases involved in $\mathrm{Fe}, \mathrm{Cu}, \mathrm{Mn}$ and $\mathrm{Zn}$ movement and reduction, respectively, in Arabidopsis thaliana and Oryza sativa. Members of the OsVIT, AtFPN, AtNRAMP, AtBCD, AtPIC, AtFRO, OsMIT, AtCOPT, AtHMA, AtCAX, AtMTP, AtZIP, AtZIF and AtECA families are targeted in intracellular membranes: vacuole (OsVIT1/2, AtFPN2, AtCAX2/4-5, AtMTP1/3/11, AtZIF1, AtNRAMP3/4, AtCOPT5 and AtZIP1), Golgi complex (AtBCD1 and AtECA3), chloroplast (AtPIC1, AtHMA1/6 and AtFRO7), thylakoid membranes (AtHMA8), mitochondrion (OsMIT and AtFRO3/8) and endoplasmic reticulum (AtHMA7). The arrows indic ate the direction of transport/reduction and each letter in the figure corresponds to the list given in the first column of the table.

In order to Cu reach the leaf symplast, plasma membrane proteins must exist to mediate $\mathrm{Cu}$ xylem unloading and $\mathrm{Cu}$ acquisition. It seems that members of the COPT family are responsible for the influx of monovalent $\mathrm{Cu}$ (Sancenon et al., 2004 and Andres-Colas et al., 2006). However, since Cu is present mainly in the divalent form in the vascular tissues, reduction must occur before it can enter the cell organelles. AtFRO7 (expressed in the chloroplasts) and AtFRO3/8 (expressed in the mitochondria) play a central role in Fe reduction, and it is hypothesized that they also participate in Cu reduction (Jeong and Connolly, 2009). Moreover, $\mathrm{Cu}$ can also be transported across the plasma membrane of leaf cells complexed with PS. Members of the YSL family were proved to be engaged in the $\mathrm{Cu}$ translocation and delivery to shoot tissues (Irtelli et al., 2009, Zheng et al., 2012 and Ando et al., 2013). Once in the cytosol of leaf cells, $\mathrm{Cu}$ is distributed with the aid of plasma membrane-localized transporters among different cell organelles. AtHMA6 (or PAA1), localized in the inner chloroplast envelope, is responsible for the delivery of $\mathrm{Cu}$ to chloroplasts (Fig. 7) (Catty et al., 2011). AtHMA8 (PAA2), closely related to AtHMA6 (PAA1), is expressed in the thylakoid membrane and supplies $\mathrm{Cu}$ to plastocyanin (Tapken et al., 2012). AtHMA1 and HvHMA1, present in the chloroplast envelope, are broad-specificity exporters of metals from chloroplasts and may play a specialized role in Cu mobilization (Mikkelsen et al., 2012). AtHMA7 (RAN1), the first functionally characterized heavy metal ATPase, is responsible for the biogenesis of ethylene receptors by supplying $\mathrm{Cu}$ at the endoplasmic reticulum and also for Cu homeostasis in seedling development (Binder et al., 2010). The rice mitochondrial Fe transporter (MIT) also appears to regulate the influx of $\mathrm{Cu}$, although more studies are needed to confirm this (Bashir et al., 2011b). The tonoplast-localized AtCOPT5 is important for $\mathrm{Cu}$ export from the vacuole and is involved in the remobilization of $\mathrm{Cu}$ ions (Garcia-Molina et al., 2011 and Klaumann et al., 2011).

Manganese reaches the leaf symplast by crossing the plasma membrane of leaf cells. To do that, members of the IRT family are thought to be expressed in the shoot tissues, mediating the transport of $\mathrm{Mn}$ ions into the cytosol of leaf cells (Pedas et al., 2008 and Barberon et al., 2011). After influx into the leaf 
symplast, Mn must be distributed into various cell compartments. In Arabidopsis, AtECA1 is localized at the endoplasmic reticulum (Li et al., 2008). The cation $/ \mathrm{H}^{+}$exchanger (CAX) transporters AtCAX2 and AtCAX4, which were originally identified as $\mathrm{Ca}^{2+}$ transporters, also have the ability to transport $\mathrm{Mn}$ into the vacuole (Fig. 7) (Connorton et al., 2012). Likewise, vacuolar $\mathrm{Mn}^{2+} / \mathrm{H}^{+}$antiporter activity in the Arabidopsis cax2 knockout mutant is significantly reduced, although it is not completely absent, compared with wildtype, suggesting the presence of additional vacuolar transporters (e.g., AtCAX5) that contribute to Mn transport ( Edmond et al., 2009). AtMTP11, which belongs to the cation diffusion facilitator (CDF) family, is implicated in the pre-vacuolar compartmentation of $\mathrm{Mn}$ as well as in Mn homeostasis mechanisms (Delhaize et al., 2007). Other MTPs also contribute to Mn transport (Gustin et al., 2011). Furthermore, it seems that the tonoplast-localized transporters OsVIT1 and OsVIT2 participate in Mn influx to the vacuole (Zhang et al., 2012). Regarding vacuolar export, AtNRAMP3 and AtNRAMP4 are expressed in the tonoplast and can transport $\mathrm{Mn}$ and other metals (Lanquar et al., 2010). AtZIP1 probably plays a role in Mn vacuolar efflux, based on the increased sensitivity to low $\mathrm{Mn}$ and increased accumulation of $\mathrm{Mn}$ in roots in the zip1 knockout line (Milner et al., 2013). The rice Fe transporter MIT appears to play a role in Mn transport into mitochondria (Bashir et al., 2011b). The mechanisms of Mn transport in the chloroplast remain unknown, despite the fact that $\mathrm{Mn}$ has a critical role in photosynthesis and the chloroplast is the one of the major sinks for Mn ( Yao et al., 2012 and Millaleo et al., 2013).

Zinc enters the leaf symplast with the aid of members of the IRT and ZIP families (Sinclair and Kramer, 2012). After reaching the leaf cytosol, the delivery of $\mathrm{Zn}$ to plant organelles is also mediated by specific transporters (Fig. 7). The vacuolar membrane transporters AtMTP1 and AtMTP3 are expressed in the vacuoles of leaf cells and play a key role in detoxification of excessive $Z n$ by accumulating $Z n$ in vacuoles (Arrivault et al., 2006 and Gustin et al., 2009). Likewise, AtHMA3 is also involved in vacuolar $\mathrm{Zn}$ sequestration (Morel et al., 2009). In Arabidopsis, AtZIF1 also seems to be expressed in the tonoplast of leaf cells. Therefore, an active role is expected from this transporter regarding the vacuolar Zn sequestration (Haydon et al., 2012). The tonoplast-localized OsVIT1 and OsVIT2 seem to transport $Z n$ into the vacuoles of plant cells (Zhang et al., 2012). In the chloroplasts of both Arabidopsis and barley, HMA1 contributes to $\mathrm{Zn}$ detoxification by exporting $\mathrm{Zn}$ from the plastids to the cytoplasm (Kim et al., 2009 and Mikkelsen et al., 2012). It has been proposed that the Golgi-localized transporter AtECA3 may have a role in the mobilization of $\mathrm{Zn}$ from the cytoplasm to the Golgi complex (Mills et al., 2008). 


\section{Beneficial elements}

Regarding the beneficial cations $\mathrm{Na}$ and $\mathrm{Co}$, little information is available about the processes regulating their movement into the leaf symplast as well as their distribution in the cell organelles (Pilon-Smits et al., 2009). Although their essentiality is not yet proved, evidence suggests that similar membrane transporters should mediate their mobilization within the plant compartments (Hänsch and Mendel, 2009 and Kronzucker and Britto, 2011).

\section{Biofortification}

Plant foods refer to plants or parts of a plant that are eaten as a food. In this category are included vegetables, fruits, grains and legumes. They constitute one of the most important nutrient sources in human diet since the beginning of civilization. Humans need several essential minerals in order to allow the proper functioning of the body, regarding growth, development and metabolism. Recommended dietary allowances (RDAs), defined as "the levels of intake of essential nutrients that, on the basis of scientific knowledge, are judged by the Food and Nutrition Board to be adequate to meet the known nutrient needs of practically all healthy persons" are established and vary between a few $\mu \mathrm{g} / \mathrm{day}$ and $1 \mathrm{~g} /$ day. If intakes are low in a certain period of time, deficiency signs may develop. On the other hand, high intakes can result in toxicity (FNB/IOM, 2006). To grow and develop, plants must take up water and essential mineral nutrients from the soil. Once taken up by plant roots, nutrients can be transported and accumulate in other parts of the plant. The final composition of the edible parts of plants is influenced and controlled by several factors, including soil fertility, plant genetics and the environment in which they grow (Karley and White, 2009, Maathuis, 2009 and Puig and Penarrubia, 2009). Although it is possible in some cases to enhance the nutritional quality of plant foods through agronomic practices and plant breeding, the soil-to-plant and plant-to-human transfer of mineral nutrients is a very complex process (Hirschi, 2009). First of all, soils differ greatly in their mineral composition and nutrients phytoavailability depends on several factors (Palm et al., 2007 and Pinto et al., 2014b). Secondly, plants possess physiological mechanisms to regulate the amounts of nutrients taken up from the soil. Hence, one can expect that attempts to alter the overall mineral composition of plant foods will be very complex (Maathuis, 2009, Pilon et al., 2009 and Pinto et al., 2014a). Thirdly, it has been recognized that the concentration of a nutrient in a food is not necessarily a reliable indicator of the value of that food as a source of the nutrient in question. This leads us to the concept of nutrient bioavailability, defined as the amount of a nutrient in ingested food that is available for utilization in metabolic processes. 
In the case of mineral nutrients, bioavailability is determined mainly by the efficiency of minerals absorption from the human gut (Hirschi, 2009). Therefore, the development of plant foods biofortification must rely on a holistic approach focusing on three concepts: (1) nutrients phytoavailability, (2) nutrients accumulation in edible tissues and (3) nutrients bioavailability. In this review, only the two first steps (nutrients phytoavailability and nutrients accumulation in edible tissues) will be discussed. For information regarding nutrients bioavailability, the reader should refer to the work of Hirschi (2009).

\section{Nutrients phytoavailability}

Five areas have been identified that are related to the uptake efficiency of cations by plants in which breeders can act. These include: (1) root morphology, (2) root hairs formation, (3) root exudates, (4) ability to release cations from non-exchangeable pools, and (5) kinetics of cation uptake. Thus, a successful biofortification strategy must understand three important aspects: (1) the spatial distribution of elements within soil profiles, (2) in which form elements are commonly found in the soil, and (3) how plant roots acquire these elements. Gathering this knowledge is of utmost importance and will enable researchers to concentrate efforts in the most limiting steps of nutrient acquisition.

Most cations in soil are incorporated in the crystal lattice structure of minerals and thus not readily available for plant uptake. The availability of these elements will be greatly influenced by the soil type and its physico-chemical properties. To simplify, cations in the soil can be classified in four groups depending on their phytoavailability: (1) water-soluble; (2) exchangeable; (3) non-exchangeable and (4) structurally bound. Water-soluble cations are directly available for both plants and microorganisms and are highly mobile within soil profiles. Exchangeable cations are those weakly adsorbed elements retained on the solid surface by relatively weak electrostatic interaction as well as cations that can be released by ion-exchange processes (Fedotov et al., 2012). Both water-soluble and exchangeable pools are usually considered to be easily phytoavailable. However, the size of both pools is negligible, accounting for as much as $0.1-0.2 \%$ and $1-2 \%$ of the total content of these elements in soil, respectively. Non-exchangeable and structurally bound pools are considered to be slowly or even non-available sources of elements for plants. These pools can only contribute to the supply of nutrients to plants in the long term (Zörb et al., 2014). As already described, the amount of cations that are phytoavailable and non-phytoavailable in the soil vary greatly among soil types. However, in all soils a dynamic equilibrium exist between the different pools, which is 
influenced by a number of soil physico-chemical properties as well as plant-soil interactions.

The main soil physico-chemical properties that control the processes of sorption and desorption of elements in the soil are: (1) $\mathrm{pH},(2)$ cation exchange capacity (CEC), (3) particle size distribution, mainly the fine granulometric fraction ( $<0.02 \mathrm{~mm}$ ), (4) organic matter (OM) and (5) oxides and hydroxides, mainly of $\mathrm{Al}, \mathrm{Fe}$ and $\mathrm{Mn}$ (Kabata-Pendias, 2004). Typically, the most mobile pool of elements occur at lower $\mathrm{pH}$. CEC reflects the dynamic equilibrium of cationic species in the soil solution, thus influencing the phytoavailability of elements. When soil $\mathrm{pH}$ becomes acid, the phytoavailability of elements usually increases due to the replacement of cations on soil binding sites by $\mathrm{H}+$ ions. Clay minerals and oxides usually possess high active surface areas, which confer them the ability to strongly bind cations. OM increases the CEC of soils because OM possesses multiple binding sites for cations, which results in a great sorption capacity (Pinto et al., 2014a).

With respect to plant-soil interactions, the rhizosphere processes such as root exudation, nutrient mobilization and rhizosphere respiration, are known to greatly influence the phytoavailability of elements (Hinsinger et al., 2009). Root exudation includes the secretion of ions, free oxygen, water, enzymes, mucilage, and a wide variety of primary and secondary metabolites (Badri and Vivanco, 2009). These exudates can increase or decrease the availability of nutrients by altering soil physico-chemical properties and soil biological processes. Typically, these root-induced changes will alter the solubility and speciation of elements in the rhizosphere in a way that nutrients are more easily available for plant uptake (Badri and Vivanco, 2009 and Kobayashi and Nishizawa, 2012).

It is now clear that one of the ways to develop more efficient plant foods, especially in terms of the nutrient density, is by improving the root exudation process. This could shift the equilibrium toward the enhance contribution of nonexchangeable and structurally bound pools to the supply of nutrients that are many times not available for plant uptake and also promote root growth as well as the formation of root hairs. Breeders can start looking at the genes encoding the plasma membrane $\mathrm{H}^{+}-$ATPase $(\mathrm{HA})$, which are responsible for the efflux of protons that promote the acidification of the rhizosphere. For instance, the breeding for an increased $\mathrm{H}^{+}$efflux from the root in order to promote the acidification of the surrounding soil may contribute to increase the availability of virtually any element required for plant growth since, as above mentioned, almost all elements are more mobile and thus phytoavailable at low soil $\mathrm{pH}$. Furthermore, $\mathrm{H}^{+}$excretion is essential in maintaining or promoting primary root 
elongation and root hair development (Palmgren, 2001). Some attempts have been already made in this area. In Arabidopsis, the protein kinase 5 (PKS5) and the chaperone DNAJ homolog 3 (J3) have been identified to play important roles in the efflux of $\mathrm{H}^{+}$by regulating the interaction between the plasma membrane HA and 14-3-3 proteins (Yang et al., 2010). Furthermore, PIN2 (an auxin efflux transporter) was also identified to be involved in the modulation of $\mathrm{H}^{+}$secretion in the root tip, maintaining primary root elongation (Xu et al., 2012a). More recently, it has been demonstrated the involvement of 14-3-3 proteins in the regulation of $\mathrm{H}^{+}$efflux and primary root elongation. Gene specificity and functional redundancy was observed among 14-3-3 proteins in primary root elongation under both control and abiotic stress conditions (van Kleeff et al., 2014). Furthermore, TFT4 and TFT7 (tomato 14-3-3 proteins), separately introduced into Arabidopsis and overexpressed, showed enhanced plasma membrane $\mathrm{HA}$ activity, $\mathrm{H}^{+}$efflux and also maintains elongation of the primary root (Xu et al., 2012b and Xu et al., 2013a). It has been also shown that abcissic acid accumulation modulates auxin transport in the root tip, which further enhances $\mathrm{H}^{+}$secretion (Xu et al., 2013b).

Another way to improve the nutrient density of plant foods is to manipulate the root system architecture toward a distribution of roots in the soil that optimizes nutrients uptake. It is important that plants have a large surface area of contact between roots and soil. This allows them to have more "options" to get the water and nutrients they need. The growth of the main and lateral roots is supported by cells produced in the root apical meristem. In this process, phytohormones play a key role. Auxin and cytokinin are assumed to be the two most important regulators of root development (Jones and Ljung, 2012). The presence of auxin concentration gradients with a maximum centered the quiescent center were revealed to be essential for the establishment and maintenance of the stem cell niche and for transit amplifying cell divisions (Petersson et al., 2009). Cytokinin acts as an antagonist of auxin. In fact, the balance between root division and differentiation appears to be primarily maintained by this antagonistic relationship, with cytokinin limiting the size of the root apical meristem and the rate of root growth (Zhang et al., 2011). Lateral roots are formed from pericycle cells adjacently located to the xylem poles. Several genes seem to be involved in this process (Moreno-Risueno et al., 2010). The identification of candidate genes will ultimately allow breeders to manipulate the root system architecture to facilitate the search for water and nutrients by plants. Efficient genotypes could be develop to have a relatively larger proportion of thin roots as well as high number of root hairs in the whole 
root system. This is thought to enhance the phytoavailability and uptake of nutrients required for plant growth and development.

For graminaceous plants, the overexpression of genes responsible for the secretion of PS will have a great impact in the solubilization of trace elements such as Fe and $\mathrm{Zn}$ that are usually low on plant foods (Nozoye et al., 2011). Candidate genes encoding ENA1 and ENA2 could be manipulated to enhance the efflux of NA in graminaceous plants such as rice. Similarly, plants overexpressing TOM1 will increase the efflux of MA, which could result in the increase solubilization of trace elements for further uptake by plant roots.

Despite these improvements, it may be also necessary to manipulate the plant uptake system. If increased uptake of nutrients by roots is an important goal for breeding of efficient plant foods, researchers may need to take a look on the role of each nutrient in plant's metabolism. For instance, the dominant role of $\mathrm{K}$ is the osmoregulation. Its role in turgor provision and water homeostasis is obvious in processes such as pressure-driven solute transport in the xylem and phloem and high levels of vacuolar $\mathrm{K}$ accumulation (Wang and Wu, 2013). Thus, the breeding for an increased activity of $\mathrm{K}$ transporters/channels (e.g., AtKT/KUP or AKT1) may contribute to an increase in cell turgor, leading to cell elongation during the growth of root hairs, conferring advantages to plant foods growth under limiting conditions (Nieves-Cordones et al., 2014). However, care should be taken to properly assess the influence of overexpressing lines in maintaining the charge balance within the plant cells, which is crucial for plant development. To cope with an increase in cation uptake, plants have also to increase the uptake of anions like chloride, nitrate, phosphate or sulphate that also act as osmolytes. This will maintain the homeostasis within plant cells. Overall, when breeding is a goal for enhance nutrient density of plant foods, ionomic studies at the whole plant level should be carried out to assess the elemental distribution within plant cells.

\section{Nutrients accumulation in edible tissues}

The successful allocation of nutrients in the edible tissues of a certain plant greatly depends on the plant tissue that is considered "edible". For instance, the edible part of carrots and potatoes are the roots. Therefore, in this case, attempts should be made to enhance the accumulation of essential nutrients in the root of these plants. By contrast, the edible tissues of leafy vegetables (e.g., lettuce or spinach) are the stems and leaves. Thus, nutrients translocation must occur to move nutrients to above-ground tissues. Finally, in other cases, seeds are the edible tissues of certain plants (e.g., rice) and nutrients loading into seeds need to occur. 
Two areas have been identified that are related to the utilization efficiency of elements by plants in which breeders can act. These include: (1) cation translocation, and (2) cation sequestration/storage. Some attempts have already been made in the two above-mentioned areas. To improve cation translocation, a $\mathrm{P}_{1 \mathrm{~B}}$-ATPase (AtHMA4) involved in the transport of $\mathrm{Zn}$ in Arabidopsis was expressed in tobacco, showing enhanced $\mathrm{Zn}$ translocation to the shoot (Siemianowski et al., 2011). Furthermore, the ectopic expression of the same export protein (AtHMA4) in tobacco also resulted in decreased $\mathrm{Cd}$ uptake/accumulation in roots and shoots (Siemianowski et al., 2014). In addition to the main aim of enhancing the nutrient density of plant foods, these findings will also allow breeders to manipulate plants in order to reduce the toxic exposure of humans via intake of plant foods-derived $\mathrm{Cd}$. Similar results have been obtained for other export proteins involved in the translocation of other cations to above-ground tissues (Maathuis, 2009, Pilon-Smits et al., 2009, Pilon et al., 2009, Kobayashi and Nishizawa, 2012, Mills et al., 2012, Takahashi et al., 2012a and Ahmad and Maathuis, 2014). To improve cation sequestration/storage in the organelles of edible plant tissues, breeders may try to manipulate vacuolar transporters. It is now widely accepted that increasing the capacity of edible tissues to sequester nutrients can promote their accumulation in these tissues. Thus, promoting the activity of vacuolar influx transporters, such as VIT, HMA, MTP and/or IREG2/FPN2, in above-ground edible tissues is seen as a promising way of food biofortification. Some research have already been made in this field. For instance, transgenic carrot and potato overexpressing the Arabidopsis vacuolar $\mathrm{H}^{+} / \mathrm{Ca}^{2+}+$ ransporter AtCAX1 showed increased Ca content compared to the wild-type (Park et al., 2004 and Park et al., 2005). In a similar way, potato tubers expressing the $A$. thalianavacuolar transporter AtCAX2B [a variant of $\mathrm{N}$-terminus truncated form of CAX2 (sCAX2)] accumulate two times more Ca than wild-type ( Kim et al., 2006a). Similar attempts have also been made to enhance the nutrients density of leaves and seeds. For instance, it has been shown that overexpression FRO genes results in an increase accumulation of $\mathrm{Fe}$ in plant leaves (Jeong and Connolly, 2009). Additionally, two important rice genes, OsVIT1 and OsVIT2, have been recently identified and characterized. It has been shown that functional disruption of both genes leads to increased $\mathrm{Fe} / \mathrm{Zn}$ accumulation in rice seeds, which might represent another strategy to biofortify Fe/Zn in staple foods (Zhang et al., 2012). However, with respect to Fe, it is also necessary to increase the biosynthesis of Fe-chelates in the shoot to increase $\mathrm{Fe}$ concentrations in seeds and/or fruits, which rely on Fe supplied via the phloem 
( Aoyama et al., 2009, Inoue et al., 2009,Morrissey et al., 2009, Ishimaru et al., 2010 and Kakei et al., 2012).

\section{Final remarks}

The main roles of essential elements have been well documented and they are unlikely to change. However, many aspects related to whole-plant nutrition needs further elucidation. For instance, some studies have already described a shift in mineral nutrition in overexpressing or knockout lines of a certain membrane transporter. Mutations that increased the content of certain elements in plant tissues usually showed negative pleiotropic effects in the content of other essential mineral elements and even on plant growth. It is now widely recognized that a complex network exists between elements and that biotic and abiotic stress are likely to change not only one element but the all ionomic profile of a plant. Despite the great advance achieved in last years, further studies are required to clarify some aspects of plant nutrition. The search for new players in the field of cation transport still represents a challenge, particularly for trace essential and beneficial elements. Evidence suggests that the beneficial elements $\mathrm{Al}$, Co and $\mathrm{Na}$ have positive effects on plant growth and stress resistance. Despite that, the mechanisms behind the beneficial effects of these elements to plants are relatively underinvestigated, especially when compared to the toxic effects that many of these elements have at high levels. It is clear that more attention should be given to the effects of beneficial elements at low levels, since this will not only clarify several basic processes of plant nutrition but also because fertilizing with beneficial nutrients may improve crop production and affect plant nutritional value.

This review summarizes the most recent discoveries regarding the function and regulation of the multiple systems involved in cation transport in plant cells. Since most of the work has been performed with the model plant $A$. thaliana, the next step should be the transfer of such knowledge to crop species. The specific properties, regulation and/or expression patterns of cation transporters/channels in different species may account for relevant agronomic advances. It is expected that in the upcoming years many promising results will be achieved in the field of biofortification. However, the application of biofortification programs will ultimately depend on the cost/benefit evaluation that farmers, consumers and politics will do. In addition, one of the most important tasks that researchers need to assure is the careful and systematic analysis of these foods before they become available to consumers. In this way, 
it seems that 'omics' methods will have a crucial role providing valuable information regarding the actual safety of these foods.

\section{References}

Ahmad and Maathuis, 2014

I. Ahmad, F.J.M. Maathuis

Cellular and tissue distribution of potassium: physiological relevance, mechanisms and regulation

J Plant Physiol, 171 (2014), pp. 708-714

Ahn et al., 2004

S.J. Ahn, R. Shin, D.P. Schachtman

Expression of KT/KUP genes in Arabidopsis and the role of root hairs in K+ uptake

Plant Physiol, 134 (2004), pp. 1135-1145

Amtmann et al., 2001

A. Amtmann, M. Fischer, E.L. Marsh, A. Stefanovic, D. Sanders, D.P. Schachtman The wheat CDNA LCT1 generates hypersensitivity to sodium in a saltsensitive yeast strain

Plant Physiol, 126 (2001), pp. 1061-1071

Ando et al., 2013

Y. Ando, S. Nagata, S. Yanagisawa, T. Yoneyama

Copper in xylem and phloem saps from rice (Oryza sativa): the effect of moderate copper concentrations in the growth medium on the accumulation of five essential metals and a speciation analysis of copper-containing compounds

Funct Plant Biol, 40 (2013), pp. 89-100

Andres-Colas et al., 2010

N. Andres-Colas, A. Perea-Garcia, S. Puig, L. Penaarubia

Deregulated copper transport affects Arabidopsis development especially in the absence of environmental cycles

Plant Physiol, 153 (2010), pp. 170-184 
Andres-Colas et al., 2006

N. Andres-Colas, V. Sancenon, S. Rodriguez-Navarro, S. Mayo, D.J. Thiele, J.R.

Ecker, et al.

The Arabidopsis heavy metal P-type ATPase HMA5 interacts with metallochaperones and functions in copper detoxification of roots Plant J, 45 (2006), pp. 225-236

Anschutz et al., 2014

U. Anschutz, D. Becker, S. Shabala

Going beyond nutrition: regulation of potassium homoeostasis as a common denominator of plant adaptive responses to environment

J Plant Physiol, 171 (2014), pp. 670-687

Aoyama et al., 2009

T. Aoyama, T. Kobayashi, M. Takahashi, S. Nagasaka, K. Usuda, Y. Kakei, et al. OsYSL18 is a rice iron(III)-deoxymugineic acid transporter specifically expressed in reproductive organs and phloem of lamina joints

Plant Mol Biol, 70 (2009), pp. 681-692

Apse and Blumwald, 2007

M.P. Apse, E. Blumwald

$\mathrm{Na}+$ transport in plants

FEBS Lett, 581 (2007), pp. 2247-2254

Araki et al., 2011

R. Araki, J. Murata, Y. Murata

A novel barley yellow stripe 1-like transporter (HvYSL2) localized to the root endodermis transports metal-phytosiderophore complexes

Plant Cell Physiol, 52 (2011), pp. 1931-1940

Aranda-Sicilia et al., 2012

M.N. Aranda-Sicilia, O. Cagnac, S. Chanroj, H. Sze, M.P. Rodriguez-Rosales, K. Venema

Arabidopsis KEA2 a homolog of bacterial KefC, encodes a $\mathrm{K}+/ \mathrm{H}+$ antiporter with a chloroplast transit peptide 
BBA Biomembr, 1818 (2012), pp. 2362-2371

Ardie et al., 2010

S.W. Ardie, S. Liu, T. Takano

Expression of the AKT1-type K(+) channel gene from Puccinellia tenuiflora,

PutAKT1, enhances salt tolerance in Arabidopsis

Plant Cell Rep, 29 (2010), pp. 865-874

Arrivault et al., 2006

S. Arrivault, T. Senger, U. Kramer

The Arabidopsis metal tolerance protein AtMTP3 maintains metal

homeostasis by mediating $\mathrm{Zn}$ exclusion from the shoot under Fe deficiency and Zn oversupply

Plant J, 46 (2006), pp. 861-879

Assunção et al., 2010

A.G.L. Assunção, E. Herrero, Y.F. Lin, B. Huettel, S. Talukdar, C. Smaczniak, et al. Arabidopsis thaliana transcription factors bZIP19 and bZIP23 regulate the adaptation to zinc deficiency

Proc Natl Acad Sci U S A, 107 (2010), pp. 10296-10301

Badri and Vivanco, 2009

D.V. Badri, J.M. Vivanco

Regulation and function of root exudates

Plant Cell Environ, 32 (2009), pp. 666-681

Barberon et al., 2011

M. Barberon, E. Zelazny, S. Robert, G. Conejero, C. Curie, J. Friml, et al. Monoubiquitin-dependent endocytosis of the iron-regulated transporter 1 (IRT1) transporter controls iron uptake in plants

Proc Natl Acad Sci U S A, 108 (2011) E450-E58

Barragan et al., 2012

V. Barragan, E.O. Leidi, Z. Andres, L. Rubio, A. De Luca, J.A. Fernandez, et al. lon exchangers NHX1 and NHX2 mediate active potassium uptake into vacuoles to regulate cell turgor and stomatal function in Arabidopsis 
Plant Cell, 24 (2012), pp. 1127-1142

Bashir et al., 2012

K. Bashir, Y. Ishimaru, N.K. Nishizawa

Molecular mechanisms of zinc uptake and translocation in rice

Plant Soil, 361 (2012), pp. 189-201

Bashir et al., 2011a

K. Bashir, Y. Ishimaru, H. Shimo, Y. Kakei, T. Senoura, R. Takahashi, et al. Rice phenolics efflux transporter 2 (PEZ2) plays an important role in solubilizing apoplasmic iron

Soil Sci Plant Nutr, 57 (2011), pp. 803-812

Bashir et al., 2011b

K. Bashir, Y. Ishimaru, H. Shimo, S. Nagasaka, M. Fujimoto, H. Takanashi, et al. The rice mitochondrial iron transporter is essential for plant growth Nat Commun (2011), p. 2

Bassil et al., 2011

E. Bassil, M.A. Ohto, T. Esumi, H. Tajima, Z. Zhu, O. Cagnac, et al. The Arabidopsis intracellular $\mathrm{Na}+/ \mathrm{H}+$ antiporters $\mathrm{NHX} 5$ and $\mathrm{NHX6}$ are endosome associated and necessary for plant growth and development Plant Cell, 23 (2011), pp. 224-239

Baxter et al., 2009

I. Baxter, P.S. Hosmani, A. Rus, B. Lahner, J.O. Borevitz, B. Muthukumar, et al. Root suberin forms an extracellular barrier that affects water relations and mineral nutrition inArabidopsis

PLoS Genet (2009), p. 2009

Benito et al., 2014

B. Benito, R. Haro, A. Amtmann, T.A. Cuin, I. Dreyer

The twins $\mathrm{K}+$ and $\mathrm{Na}+$ in plants

J Plant Physiol, 171 (2014), pp. 723-731 
Bernal et al., 2012

M. Bernal, D. Casero, V. Singh, G.T. Wilson, A. Grande, H.J. Yang, et al.

Transcriptome sequencing identifies SPL7-regulated copper acquisition

genes FRO4/FRO5 and the copper dependence of iron homeostasis

in Arabidopsis

Plant Cell, 24 (2012), pp. 738-761

Bhatia et al., 2005

N.P. Bhatia, K.B. Walsh, A.J.M. Baker

Detection and quantification of ligands involved in nickel detoxification in a herbaceous Ni hyperaccumulator Stackhousia tryonii Bailey

J Exp Bot, 56 (2005), pp. 1343-1349

Binder et al., 2010

B.M. Binder, F.I. Rodriguez, A.B. Bleecker

The copper transporter RAN1 is essential for biogenesis of ethylene receptors in Arabidopsis

J Biol Chem, 285 (2010), pp. 37263-37270

Cailliatte et al., 2010

R. Cailliatte, A. Schikora, J.F. Briat, S. Mari, C. Curie

High-affinity manganese uptake by the metal transporter NRAMP1 is essential for Arabidopsisgrowth in low manganese conditions

Plant Cell, 22 (2010), pp. 904-917

Catty et al., 2011

P. Catty, S. Boutigny, R. Miras, J. Joyard, N. Rolland, D. Seigneurin-Berny

Biochemical characterization of AtHMA6/PAA1, a chloroplast envelope $\mathrm{Cu}(\mathrm{I})$ -

ATPase

J Biol Chem, 286 (2011), pp. 36188-36197

Cellier et al., 2004

F. Cellier, G. Conejero, L. Ricaud, D.T. Luu, M. Lepetit, F. Gosti, et al.

Characterization of AtCHX17, a member of the cation/ $\mathrm{H}+$ exchangers, $\mathrm{CHX}$ family, fromArabidopsis thaliana suggests a role in $\mathrm{K}+$ homeostasis

Plant J, 39 (2004), pp. 834-846 
Centofanti et al., 2013

T. Centofanti, Z. Sayers, M.I. Cabello-Conejo, P. Kidd, N.K. Nishizawa, Y. Kakei,et al.

Xylem exudate composition and root-to-shoot nickel translocation in Alyssum species

Plant Soil, 373 (2013), pp. 59-75

Chen et al., 2009

J. Chen, L.G. Li, Z.H. Liu, Y.J. Yuan, L.L. Guo, D.D. Mao, et al.

Magnesium transporter AtMGT9 is essential for pollen development in Arabidopsis

Cell Res, 19 (2009), pp. 887-898

Cheng et al., 2005

N.H. Cheng, J.K. Pittman, T. Shigaki, J. Lachmansingh, S. LeClere, B. Lahner, et al.

Functional association of Arabidopsis CAX1 and CAX3 is required for normal growth and ion homeostasis

Plant Physiol, 138 (2005), pp. 2048-2060

Chu et al., 2010

H.H. Chu, J. Chiecko, T. Punshon, A. Lanzirotti, B. Lahner, D.E. Salt, et al.

Successful reproduction requires the function of Arabidopsis YELLOW STRIPE-LIKE1 and YELLOW STRIPE-LIKE3 metal-nicotianamine transporters in both vegetative and reproductive structures

Plant Physiol, 154 (2010), pp. 197-210

Conn et al., 2011a

S.J. Conn, V. Conn, S.D. Tyerman, B.N. Kaiser, R.A. Leigh, M. Gilliham Magnesium transporters, MGT2/MRS2-1 and MGT3/MRS2-5, are important for magnesium partitioning within Arabidopsis thaliana mesophyll vacuoles New Phytol, 190 (2011), pp. 583-594

Conn et al., 2011b

S.J. Conn, M. Gilliham, A. Athman, A.W. Schreiber, U. Baumann, I. Moller, et al. 
Cell-specific vacuolar calcium storage mediated by CAX1 regulates apoplastic calcium concentration, gas exchange, and plant productivity in Arabidopsis

Plant Cell, 23 (2011), pp. 240-257

Connorton et al., 2012

J.M. Connorton, R.E. Webster, N.H. Cheng, J.K. Pittman

Knockout of multiple Arabidopsis cation/ $\mathrm{H}+$ exchangers suggests isoformspecific roles in metal stress response, germination and seed mineral nutrition

PLOS ONE (2012), p. 2012

Cosio et al., 2005

C. Cosio, L. DeSantis, B. Frey, S. Diallo, C. Keller

Distribution of cadmium in leaves of Thiaspi caerulescens

J Exp Bot, 56 (2005), pp. 765-775

Davenport et al., 2007

R.J. Davenport, A. Munoz-Mayor, D. Jha, P.A. Essah, A. Rus, M. Tester

The $\mathrm{Na}+$ transporter AtHKT1;1 controls retrieval of $\mathrm{Na}+$ from the xylem in Arabidopsis

Plant Cell Environ, 30 (2007), pp. 497-507

Dayod et al., 2010

M. Dayod, S.D. Tyerman, R.A. Leigh, M. Gilliham

Calcium storage in plants and the implications for calcium biofortification Protoplasma, 247 (2010), pp. 215-231

Deinlein et al., 2012

U. Deinlein, M. Weber, H. Schmidt, S. Rensch, A. Trampczynska, T.H. Hansen, et al.

Elevated nicotianamine levels in Arabidopsis halleri roots play a key role in zinc hyperaccumulation

Plant Cell, 24 (2012), pp. 708-723

del Pozo et al., 2010 
T. del Pozo, V. Cambiazo, M. Gonzalez

Gene expression profiling analysis of copper homeostasis in Arabidopsis thaliana

Biochem Biophys Res Commun, 393 (2010), pp. 248-252

Delhaize et al., 2007

E. Delhaize, B.D. Gruber, J.K. Pittman, R.G. White, H. Leung, Y.S. Miao, et al.

A role for the AtMTP11 gene of Arabidopsis in manganese transport and tolerance

Plant J, 51 (2007), pp. 198-210

Demidchik and Maathuis, 2007

V. Demidchik, F.J.M. Maathuis

Physiological roles of nonselective cation channels in plants: from salt stress to signalling and development

New Phytol, 175 (2007), pp. 387-404

Deng et al., 2006

W. Deng, K.M. Luo, D.M. Li, X.L. Zheng, X.Y. Wei, W. Smith, et al.

Overexpression of an Arabidopsis magnesium transport gene, AtMGT1,

in Nicotiana benthamiana confers Al tolerance

J Exp Bot, 57 (2006), pp. 4235-4243

Drummond et al., 2006

R.S.M. Drummond, A. Tutone, Y.C. Li, R.C. Gardner

A putative magnesium transporter AtMRS2-11 is localized to the plant chloroplast envelope membrane system

Plant Sci, 170 (2006), pp. 78-89

Durrett et al., 2007

T.P. Durrett, W. Gassmann, E.E. Rogers

The FRD3-mediated efflux of citrate into the root vasculature is necessary for efficient iron translocation

Plant Physiol, 144 (2007), pp. 197-205

Duy et al., 2011 
D. Duy, R. Stube, G. Wanner, K. Philippar

The chloroplast permease PIC1 regulates plant growth and development by directing homeostasis and transport of iron

Plant Physiol, 155 (2011), pp. 1709-1722

Edmond et al., 2009

C. Edmond, T. Shigaki, S. Ewert, M.D. Nelson, J.M. Connorton, V. Chalova, et al. Comparative analysis of CAX2-like cation transporters indicates functional and regulatory diversity

Biochem J, 418 (2009), pp. 145-154

Elbaz et al., 2006

B. Elbaz, N. Shoshani-Knaani, O. David-Assael, T. Mizrachy-Dagri, K. Mizrahi, H. Saul, et al.

High expression in leaves of the zinc hyperaccumulator Arabidopsis halleri of AhMHX, a homolog of an Arabidopsis thaliana vacuolar metal/proton exchanger

Plant Cell Environ, 29 (2006), pp. 1179-1190

Fedotov et al., 2012

P.S. Fedotov, W. Kordel, M. Miro, W.J.G.M. Peijnenburg, R. Wennrich, P.M. Huang Extraction and fractionation methods for exposure assessment of trace metals, metalloids, and hazardous organic compounds in terrestrial environments

Crit Rev Environ Sci Technol, 42 (2012), pp. 1117-1171

FNB/IOM, 2006

FNB/IOM

Part III. Vitamins and minerals. Dietary reference intakes: the essential guide to nutrient requirements

The National Academies Press (2006), pp. 167-422

Forde, 2014

B.G. Forde

Glutamate signalling in roots 
J Exp Bot, 65 (2014), pp. 779-787

Fox and Guerinot, 1998

T.C. Fox, M.L. Guerinot

Molecular biology of cation transport in plants

Annu Rev Plant Phys, 49 (1998), pp. 669-696

Fukao et al., 2011

Y. Fukao, A. Ferjani, R. Tomioka, N. Nagasaki, R. Kurata, Y. Nishimori, et al.

ITRAQ analysis reveals mechanisms of growth defects due to excess zinc in Arabidopsis

Plant Physiol, 155 (2011), pp. 1893-1907

Fulgenzi et al., 2008

F.R. Fulgenzi, M.L. Peralta, S. Mangano, C.H. Danna, A.J. Vallejo, P.

Puigdomenech, et al.

The ionic environment controls the contribution of the barley HvHAK1 transporter to potassium acquisition

Plant Physiol, 147 (2008), pp. 252-262

Gajdanowicz et al., 2011

P. Gajdanowicz, E. Michard, M. Sandmann, M. Rocha, L.G.G. Correa, S.J.

Ramirez-Aguilar, et al.

Potassium $(\mathrm{K}+)$ gradients serve as a mobile energy source in plant vascular tissues

Proc Natl Acad Sci U S A, 108 (2011), pp. 864-869

Garcia-Molina et al., 2011

A. Garcia-Molina, N. Andres-Colas, A. Perea-Garcia, S. del Valle-Tascon, L. Penarrubia, S. Puig

The intracellular Arabidopsis COPT5 transport protein is required for photosynthetic electron transport under severe copper deficiency Plant J, 65 (2011), pp. 848-860 
M. Gebert, K. Meschenmoser, S. Svidova, J. Weghuber, R. Schweyen, K. Eifler, et al.

A root-expressed magnesium transporter of the MRS2/MGT gene family in Arabidopsis thalianaallows for growth in low-Mg ${ }^{2+}$ environments Plant Cell, 21 (2009), pp. 4018-4030

Geiger et al., 2009

D. Geiger, D. Becker, D. Vosloh, F. Gambale, K. Palme, M. Rehers, et al. Heteromeric AtKC1.AKT1 channels in Arabidopsis roots facilitate growth under $\mathrm{K}+$-limiting conditions

J Biol Chem, 284 (2009), pp. 21288-21295

Gendre et al., 2007

D. Gendre, P. Czernic, G. Conejero, K. Pianelli, J.F. Briat, M. Lebrun, et al. TcYSL3, a member of the YSL gene family from the hyperaccumulator Thlaspi caerulescens, encodes a nicotianamine-Ni/Fe transporter

Plant J, 49 (2007), pp. 1-15

Ghasemi et al., 2009

R. Ghasemi, S.M. Ghaderian, U. Kramer Interference of nickel with copper and iron homeostasis contributes to metal toxicity symptoms in the nickel hyperaccumulator plant Alyssum inflatum New Phytol, 184 (2009), pp. 566-580

Guo et al., 2008

W.J. Guo, M. Meetam, P.B. Goldsbrough

Examining the specific contributions of

individual Arabidopsis metallothioneins to copper distribution and metal tolerance

Plant Physiol, 146 (2008), pp. 1697-1706

Gustin et al., 2009

J.L. Gustin, M.E. Loureiro, D. Kim, G. Na, M. Tikhonova, D.E. Salt MTP1-dependent $Z n$ sequestration into shoot vacuoles suggests dual roles in $\mathrm{Zn}$ tolerance and accumulation in $\mathrm{Zn}$-hyperaccumulating plants

Plant J, 57 (2009), pp. 1116-1127 
Gustin et al., 2011

J.L. Gustin, M.J. Zanis, D.E. Salt

Structure and evolution of the plant cation diffusion facilitator family of ion transporters

BMC Evol Biol (2011), p. 2011

Haferkamp and Linka, 2012

I. Haferkamp, N. Linka

Functional expression and characterisation of membrane transport proteins Plant Biol, 14 (2012), pp. 675-690

Hamamoto and Uozumi, 2014

S. Hamamoto, N. Uozumi

Organelle-localized potassium transport systems in plants

J Plant Physiol, 171 (2014), pp. 743-747

Hänsch and Mendel, 2009

R. Hänsch, R.R. Mendel

Physiological functions of mineral micronutrients $(\mathrm{Cu}, \mathrm{Zn}, \mathrm{Mn}, \mathrm{Fe}, \mathrm{Ni}, \mathrm{Mo}, \mathrm{B}$, Cl)

Curr Opin Plant Biol, 12 (2009), pp. 259-266

Haro et al., 2005

R. Haro, M.A. Banuelos, M.A.E. Senn, J. Barrero-Gil, A. Rodriguez-Navarro HKT1 mediates sodium uniport in roots. Pitfalls in the expression of HKT1 in yeast

Plant Physiol, 139 (2005), pp. 1495-1506

Harris et al., 2012

W.R. Harris, R.D. Sammons, R.C. Grabiak

A speciation model of essential trace metal ions in phloem

J Inorg Biochem, 116 (2012), pp. 140-150 
Haydon et al., 2012

M.J. Haydon, M. Kawachi, M. Wirtz, S. Hillmer, R. Hell, U. Kramer

Vacuolar nicotianamine has critical and distinct roles under iron deficiency and for zinc sequestration in Arabidopsis

Plant Cell, 24 (2012), pp. 724-737

Hedrich and Marten, 2011

R. Hedrich, I. Marten

TPC1-SV channels gain shape

Mol Plant, 4 (2011), pp. 428-441

Hinsinger et al., 2009

P. Hinsinger, A.G. Bengough, D. Vetterlein, I.M. Young

Rhizosphere: biophysics, biogeochemistry and ecological relevance

Plant Soil, 321 (2009), pp. 117-152

Hirschi, 2009

K.D. Hirschi

Nutrient biofortification of food crops

Annu Rev Nutr, 29 (2009), pp. 401-421

Horie et al., 2011

T. Horie, M. Sugawara, T. Okada, K. Taira, P. Kaothien-Nakayama, M.

Katsuhara, et al.

Rice sodium-insensitive potassium transporter, OsHAK5, confers increased salt tolerance in tobacco BY2 cells

J Biosci Bioeng, 111 (2011), pp. 346-356

Hu et al., 2012

Y.T. Hu, F. Ming, W.W. Chen, J.Y. Yan, Z.Y. Xu, G.X. Li, et al. TcOPT3, a member of oligopeptide transporters from the hyperaccumulator Thlaspi caerulescens, is a novel $\mathrm{Fe} / \mathrm{Zn} / \mathrm{Cd} / \mathrm{Cu}$ transporter PLOS ONE (2012), p. 2012

Inoue et al., 2009 
H. Inoue, T. Kobayashi, T. Nozoye, M. Takahashi, Y. Kakei, K. Suzuki, et al. Rice OsYSL15 is an iron-regulated iron(III)-deoxymugineic acid transporter expressed in the roots and is essential for iron uptake in early growth of the seedlings

J Biol Chem, 284 (2009), pp. 3470-3479

Irtelli et al., 2009

B. Irtelli, W.A. Petrucci, F. Navari-Izzo

Nicotianamine and histidine/proline are, respectively, the most important copper chelators in xylem sap of Brassica carinata under conditions of copper deficiency and excess

J Exp Bot, 60 (2009), pp. 269-277

Ishimaru et al., 2011

Y. Ishimaru, Y. Kakei, H. Shimo, K. Bashir, Y. Sato, Y. Sato, et al.

A rice phenolic efflux transporter is essential for solubilizing precipitated apoplasmic iron in the plant stele

J Biol Chem, 286 (2011), pp. 24649-24655

Ishimaru et al., 2010

Y. Ishimaru, H. Masuda, K. Bashir, H. Inoue, T. Tsukamoto, M. Takahashi, et al. Rice metal-nicotianamine transporter, OsYSL2, is required for the longdistance transport of iron and manganese

Plant J, 62 (2010), pp. 379-390

Ishimaru et al., 2012

Y. Ishimaru, R. Takahashi, K. Bashir, H. Shimo, T. Senoura, K. Sugimoto, et al. Characterizing the role of rice NRAMP5 in manganese, iron and cadmium transport

Sci Rep (2012), p. 2012

Jabnoune et al., 2009

M. Jabnoune, S. Espeout, D. Mieulet, C. Fizames, J.L. Verdeil, G. Conejero, et al. Diversity in expression patterns and functional properties in the rice HKT transporter family 
Plant Physiol, 150 (2009), pp. 1955-1971

Jeanguenin et al., 2011

L. Jeanguenin, C. Alcon, G. Duby, M. Boeglin, I. Cherel, I. Gaillard, et al.

AtKC1 is a general modulator of Arabidopsis inward Shaker channel activity

Plant J, 67 (2011), pp. 570-582

Jeong and Connolly, 2009

J. Jeong, E.L. Connolly

Iron uptake mechanisms in plants: functions of the FRO family of ferric reductases

Plant Sci, 176 (2009), pp. 709-714

Jeong and Guerinot, 2008

J. Jeong, M.L. Guerinot

Biofortified and bioavailable: the gold standard, for plant-based diets Proc Natl Acad Sci U S A, 105 (2008), pp. 1777-1778

Johansson et al., 2006

I. Johansson, K. Wulfetange, F. Poree, E. Michard, P. Gajdanowicz, B. Lacombe, et al.

External K+ modulates the activity of the Arabidopsis potassium channel SKOR via an unusual mechanism

Plant J, 46 (2006), pp. 269-281

Jones and Ljung, 2012

B. Jones, K. Ljung

Subterranean space exploration: the development of root system architecture Curr Opin Plant Biol, 15 (2012), pp. 97-102

Jung et al., 2012

H.I. Jung, S.R. Gayomba, M.A. Rutzke, E. Craft, L.V. Kochian, O.K. Vatamaniuk COPT6 is a plasma membrane transporter that functions in copper homeostasis in Arabidopsisand is a novel target of SQUAMOSA promoterbinding protein-like 7

J Biol Chem, 287 (2012), pp. 33252-33267 
Kabata-Pendias, 2004

A. Kabata-Pendias

Soil-plant transfer of trace elements-an environmental issue

Geoderma, 122 (2004), pp. 143-149

Kakei et al., 2012

Y. Kakei, Y. Ishimaru, T. Kobayashi, T. Yamakawa, H. Nakanishi, N.K. Nishizawa OsYSL16 plays a role in the allocation of iron

Plant Mol Biol, 79 (2012), pp. 583-594

Karley and White, 2009

A.J. Karley, P.J. White

Moving cationic minerals to edible tissues: potassium, magnesium, calcium

Curr Opin Plant Biol, 12 (2009), pp. 291-298

Kawachi et al., 2009

M. Kawachi, Y. Kobae, H. Mori, R. Tomioka, Y. Lee, M. Maeshima

A mutant strain Arabidopsis thaliana that lacks vacuolar membrane zinc transporter MTP1 revealed the latent tolerance to excessive zinc

Plant Cell Physiol, 50 (2009), pp. 1156-1170

Kim et al., 2006a

C.K. Kim, J.S. Han, H.S. Lee, J.Y. Oh, T. Shigaki, S.H. Park, et al.

Expression of an Arabidopsis CAX2 variant in potato tubers increases

calcium levels with no accumulation of manganese

Plant Cell Rep, 25 (2006), pp. 1226-1232

Kim et al., 2006b

S.A. Kim, T. Punshon, A. Lanzirotti, L.T. Li, J.M. Alonso, J.R. Ecker, et al.

Localization of iron in Arabidopsis seed requires the vacuolar membrane transporter VIT1

Science, 314 (2006), pp. 1295-1298

Kim et al., 2009

Y.Y. Kim, H. Choi, S. Segami, H.T. Cho, E. Martinoia, M. Maeshima, et al. 
AtHMA1 contributes to the detoxification of excess $\mathrm{Zn}$ (II) in Arabidopsis Plant J, 58 (2009), pp. 737-753

Klaumann et al., 2011

S. Klaumann, S.D. Nickolaus, S.H. Furst, S. Starck, S. Schneider, H.E. Neuhaus, et al.

The tonoplast copper transporter COPT5 acts as an exporter and is required for interorgan allocation of copper in Arabidopsis thaliana

New Phytol, 192 (2011), pp. 393-404

Kobayashi and Nishizawa, 2012

T. Kobayashi, N.K. Nishizawa

Iron uptake, translocation, and regulation in higher plants

Annu Rev Plant Biol, 63 (2012), pp. 131-152

Krebs et al., 2010

M. Krebs, D. Beyhl, E. Gorlich, K.A.S. Al-Rasheid, I. Marten, Y.D. Stierhof, et al. Arabidopsis V-ATPase activity at the tonoplast is required for efficient nutrient storage but not for sodium accumulation

Proc Natl Acad Sci U S A, 107 (2010), pp. 3251-3256

Kronzucker and Britto, 2011

H.J. Kronzucker, D.T. Britto

Sodium transport in plants: a critical review

New Phytol, 189 (2011), pp. 54-81

Lanquar et al., 2005

V. Lanquar, F. Lelievre, S. Bolte, C. Hames, C. Alcon, D. Neumann, et al. Mobilization of vacuolar iron by AtNRAMP3 and AtNRAMP4 is essential for seed germination on low iron

EMBO J, 24 (2005), pp. 4041-4051

Lanquar et al., 2010

V. Lanquar, M.S. Ramos, F. Lelievre, H. Barbier-Brygoo, A. Krieger-Liszkay, U. Kramer, et al. 
Export of vacuolar manganese by AtNRAMP3 and AtNRAMP4 is required for optimal photosynthesis and growth under manganese deficiency

Plant Physiol, 152 (2010), pp. 1986-1999

Larbi et al., 2010

A. Larbi, F. Morales, A. Abadia, J. Abadia

Changes in iron and organic acid concentrations in xylem sap and apoplastic fluid of iron-deficient Beta vulgaris plants in response to iron resupply

J Plant Physiol, 167 (2010), pp. 255-260

Larras et al., 2013

F. Larras, N. Regier, S. Planchon, J. Pote, J. Renaut, C. Cosio

Physiological and proteomic changes suggest an important role of cell walls in the high tolerance to metals of Elodea nuttallii

J Hazard Mater, 263 (2013), pp. 575-583

Lee and An, 2009

S. Lee, G. An

Over-expression of OsIRT1 leads to increased iron and zinc accumulations in rice

Plant Cell Environ, 32 (2009), pp. 408-416

Lee et al., 2010

S. Lee, S.A. Kim, J. Lee, M.L. Guerinot, G. An

Zinc deficiency-inducible OsZIP8 encodes a plasma membrane-localized zinc transporter in rice

Mol Cells, 29 (2010), pp. 551-558

Lee et al., 2007

S.M. Lee, H.S. Kim, H.J. Han, B.C. Moon, C.Y. Kim, J.F. Harper, et al. Identification of a calmodulin-regulated autoinhibited Ca2+-ATPase (ACA11) that is localized to vacuole membranes in Arabidopsis

FEBS Lett, 581 (2007), pp. 3943-3949

Li et al., 2008 
X.Y. Li, S. Chanroj, Z.Y. Wu, S.M. Romanowsky, J.F. Harper, H. Sze

A distinct endosomal $\mathrm{Ca2}+/ \mathrm{Mn2}+$ pump affects root growth through the secretory process

Plant Physiol, 147 (2008), pp. 1675-1689

Lin et al., 2009

Y.F. Lin, H.M. Liang, S.Y. Yang, A. Boch, S. Clemens, C.C. Chen, et al.

Arabidopsis IRT3 is a zinc-regulated and plasma membrane localized

zinc/iron transporter

New Phytol, 182 (2009), pp. 392-404

Ma et al., 2009

W. Ma, A. Smigel, R. Verma, G.A. Berkowitz

Cyclic nucleotide gated channels and related signaling components in plant innate immunity

Plant Signal Behav, 4 (2009), pp. 277-282

Maathuis, 2009

F.J.M. Maathuis

Physiological functions of mineral macronutrients

Curr Opin Plant Biol, 12 (2009), pp. 250-258

Manohar et al., 2011

M. Manohar, T. Shigaki, K.D. Hirschi

Plant cation/H+ exchangers (CAXs): biological functions and genetic manipulations

Plant Biol, 13 (2011), pp. 561-569

Mao et al., 2008

D.D. Mao, L.F. Tian, L.G. Li, J. Chen, P.Y. Deng, D.P. Li, et al.

AtMGT7: an Arabidopsis gene encoding a low-affinity magnesium transporter J Integr Plant Biol, 50 (2008), pp. 1530-1538

Mari et al., 2006

S. Mari, D. Gendre, K. Pianelli, L. Ouerdane, R. Lobinski, J.F. Briat, et al. 
Root-to-shoot long-distance circulation of nicotianamine and nicotianaminenickel chelates in the metal hyperaccumulator Thlaspi caerulescens

J Exp Bot, 57 (2006), pp. 4111-4122

Martinoia et al., 2012

E. Martinoia, S. Meyer, A. De Angeli, R. Nagy

Vacuolar transporters in their physiological context

Annu Rev Plant Biol, 63 (2012), pp. 183-213

McAinsh and Pittman, 2009

M.R. McAinsh, J.K. Pittman

Shaping the calcium signature

New Phytol, 181 (2009), pp. 275-294

Mian et al., 2011

A. Mian, R.J.F.J. Oomen, S. Isayenkov, H. Sentenac, F.J.M. Maathuis, A.A. Very

Over-expression of an $\mathrm{Na+-}$ and $\mathrm{K}+-$ permeable HKT transporter in barley improves salt tolerance

Plant J, 68 (2011), pp. 468-479

Mikkelsen et al., 2012

M.D. Mikkelsen, P. Pedas, M. Schiller, E. Vincze, R.F. Mills, S. Borg, et al.

Barley HvHMA1 is a heavy metal pump involved in mobilizing organellar $\mathrm{Zn}$ and $\mathrm{Cu}$ and plays a role in metal loading into grains

PLOS ONE (2012), p. 2012

Millaleo et al., 2013

R. Millaleo, M. Reyes-Diaz, M. Alberdi, A.G. Ivanov, M. Krol, N.P.A. Huner Excess manganese differentially inhibits photosystem I versus II in Arabidopsis thaliana

J Exp Bot, 64 (2013), pp. 343-354

Mills et al., 2008

R.F. Mills, M.L. Doherty, R.L. Lopez-Marques, T. Weimar, P. Dupree, M.G.

Palmgren, et al. 
ECA3, a Golgi-localized P-2A-type ATPase, plays a crucial role in manganese nutrition inArabidopsis

Plant Physiol, 146 (2008), pp. 116-128

Mills et al., 2012

R.F. Mills, K.A. Peaston, J. Runions, L.E. Williams

HvHMA2, a P-1B-ATPase from barley, is highly conserved among cereals and functions in $\mathrm{Zn}$ and $\mathrm{Cd}$ transport

PLOS ONE (2012), p. 7

Milner et al., 2013

M.J. Milner, J. Seamon, E. Craft, L.V. Kochian

Transport properties of members of the ZIP family in plants and their role in

$\mathrm{Zn}$ and Mn homeostasis

J Exp Bot, 64 (2013), pp. 369-381

Moller et al., 2009

I.S. Moller, M. Gilliham, D. Jha, G.M. Mayo, S.J. Roy, J.C. Coates, et al.

Shoot $\mathrm{Na}+$ exclusion and increased salinity tolerance engineered by cell typespecific alteration of $\mathrm{Na}+$ transport in Arabidopsis

Plant Cell, 21 (2009), pp. 2163-2178

Morel et al., 2009

M. Morel, J. Crouzet, A. Gravot, P. Auroy, N. Leonhardt, A. Vavasseur, et al.

AtHMA3, a P-1B-ATPase allowing $\mathrm{Cd} / \mathrm{Zn} / \mathrm{Co} / \mathrm{Pb}$ vacuolar storage

in Arabidopsis

Plant Physiol, 149 (2009), pp. 894-904

Moreno-Risueno et al., 2010

M.A. Moreno-Risueno, J.M. Van Norman, A. Moreno, J.Y. Zhang, S.E. Ahnert, P.N.

Benfey

Oscillating gene expression determines competence for

periodic Arabidopsis root branching

Science, 329 (2010), pp. 1306-1311

Morrissey et al., 2009 
J. Morrissey, I.R. Baxter, J. Lee, L.T. Li, B. Lahner, N. Grotz, et al.

The ferroportin metal efflux proteins function in iron and cobalt homeostasis in Arabidopsis

Plant Cell, 21 (2009), pp. 3326-3338

Mortimer et al., 2008

J.C. Mortimer, A. Laohavisit, N. Macpherson, A. Webb, C. Brownlee, N.H. Battey, et al.

Annexins: multifunctional components of growth and adaptation

J Exp Bot, 59 (2008), pp. 533-544

Mukherjee et al., 2006

I. Mukherjee, N.H. Campbell, J.S. Ash, E.L. Connolly

Expression profiling of the Arabidopsis ferric chelate reductase (FRO) gene family reveals differential regulation by iron and copper

Planta, 223 (2006), pp. 1178-1190

Murata et al., 2008

Y. Murata, E. Harada, K. Sugase, K. Namba, M. Horikawa, J.F. Ma, et al.

Specific transporter for iron(III)-phytosiderophore complex involved in iron uptake by barley roots

Pure Appl Chem, 80 (2008), pp. 2689-2697

Nieves-Cordones et al., 2010

M. Nieves-Cordones, F. Aleman, V. Martinez, F. Rubio

The Arabidopsis thaliana HAK5 $\mathrm{K}+$ transporter is required for plant growth and $\mathrm{K}+$ acquisition from low $\mathrm{K}+$ solutions under saline conditions

Mol Plant, 3 (2010), pp. 326-333

Nieves-Cordones et al., 2014

M. Nieves-Cordones, F. Aleman, V. Martinez, F. Rubio

$\mathrm{K}+$ uptake in plant roots. The systems involved, their regulation and parallels in other organisms

J Plant Physiol, 171 (2014), pp. 688-695 
S. Nishida, A. Aisu, T. Mizuno

Induction of IRT1 by the nickel-induced iron-deficient response

in Arabidopsis

Plant Signal Behav, 7 (2012), pp. 329-331

Nishiyama et al., 2012

R. Nishiyama, M. Kato, S. Nagata, S. Yanagisawa, T. Yoneyama

Identification of $\mathrm{Zn}$-nicotianamine and Fe-2'-deoxymugineic acid in the phloem sap from rice plants (Oryza sativa L.)

Plant Cell Physiol, 53 (2012), pp. 381-390

Nozoye et al., 2011

T. Nozoye, S. Nagasaka, T. Kobayashi, M. Takahashi, Y. Sato, Y. Sato, et al. Phytosiderophore efflux transporters are crucial for iron acquisition in graminaceous plants

J Biol Chem, 286 (2011), pp. 5446-5454

Nozoye et al., 2013

T. Nozoye, H. Nakanishi, N.K. Nishizawa

Characterizing the crucial components of iron homeostasis in the maize mutants ys 1 and ys 3

PLOS ONE (2013), p. 2013

Oomen et al., 2009

R.J.F.J. Oomen, J. Wu, F. Lelievre, S. Blanchet, P. Richaud, H. Barbier-Brygoo, et al.

Functional characterization of NRAMP3 and NRAMP4 from the metal hyperaccumulator Thlaspi caerulescens

New Phytol, 181 (2009), pp. 637-650

Pal and Rai, 2010

R. Pal, J.P.N. Rai

Phytochelatins peptides involved in heavy metal detoxification Appl Biochem Biotechnol, 160 (2010), pp. 945-963 
Palm et al., 2007

C. Palm, P. Sanchez, S. Ahamed, A. Awiti

Soils A contemporary perspective

Annu Rev Environ Resour, 32 (2007), pp. 99-129

Palmgren, 2001

M.G. Palmgren

Plant plasma membrane H+-ATPases: powerhouses for nutrient uptake

Annu Rev Plant Phys, 52 (2001), pp. 817-845

Park et al., 2005

S. Park, T.S. Kang, C.K. Kim, J.S. Han, S. Kim, R.H. Smith, et al.

Genetic manipulation for enhancing calcium content in potato tuber

J Agric Food Chem, 53 (2005), pp. 5598-5603

Park et al., 2004

S. Park, C.K. Kim, L.M. Pike, R.H. Smith, K.D. Hirschi

Increased calcium in carrots by expression of an Arabidopsis $\mathrm{H}+/ \mathrm{Ca} 2+$

transporter

Mol Breed, 14 (2004), pp. 275-282

Pedas et al., 2008

P. Pedas, C.K. Ytting, A.T. Fuglsang, T.P. Jahn, J.K. Schjoerring, S. Husted Manganese efficiency in barley: identification and characterization of the metal ion transporter HvIRT1

Plant Physiol, 148 (2008), pp. 455-466

Petersson et al., 2009

S.V. Petersson, A.I. Johansson, M. Kowalczyk, A. Makoveychuk, J.Y. Wang, T. Moritz, et al.

An auxin gradient and maximum in the Arabidopsis root apex shown by highresolution cell-specific analysis of IAA distribution and synthesis

Plant Cell, 21 (2009), pp. 1659-1668

Pilon-Smits et al., 2009 
E.A.H. Pilon-Smits, C.F. Quinn, W. Tapken, M. Malagoli, M. Schiavon

Physiological functions of beneficial elements

Curr Opin Plant Biol, 12 (2009), pp. 267-274

Pilon et al., 2009

M. Pilon, C.M. Cohu, K. Ravet, S.E. Abdel-Ghany, F. Gaymard

Essential transition metal homeostasis in plants

Curr Opin Plant Biol, 12 (2009), pp. 347-357

Pineau et al., 2012

C. Pineau, S. Loubet, C. Lefoulon, C. Chalies, C. Fizames, B. Lacombe, et al. Natural variation at the FRD3 MATE transporter locus reveals cross-talk between Fe homeostasis and $\mathrm{Zn}$ tolerance in Arabidopsis thaliana PLOS Genet (2012), p. 2012

Pinto et al., 2014a

E. Pinto, A.A.R.M. Aguiar, I.M.P.L.V.O. Ferreira

Influence of soil chemistry and plant physiology in the phytoremediation of $\mathrm{Cu}, \mathrm{Mn}$, and $\mathrm{Zn}$

Crit Rev Plant Sci, 33 (2014), pp. 351-373

Pinto et al., 2014b

E. Pinto, A.A. Almeida, A.A.R.M. Aguiar, I.M.P.L.V.O. Ferreira

Changes in macrominerals, trace elements and pigments content during lettuce (Lactuca sativaL.) growth: influence of soil composition

Food Chem, 152 (2014), pp. 603-611

Pinto et al., 2015

E. Pinto, A.A. Almeida, I.M.P.L.V.O. Ferreira

Assessment of metal(loid)s phytoavailability in intensive agricultural soils by the application of single extractions to rhizosphere soil

Ecotoxicol Environ Saf, 113 (2015), pp. 418-424

Pittman, 2005

J.K. Pittman 
Managing the manganese: molecular mechanisms of manganese transport and homeostasis

New Phytol, 167 (2005), pp. 733-742

Pittman, 2011

J.K. Pittman

Vacuolar Ca2+ uptake

Cell Calcium, 50 (2011), pp. 139-146

Pottosin and Dobrovinskaya, 2014

I. Pottosin, O. Dobrovinskaya

Non-selective cation channels in plasma and vacuolar membranes and their contribution to $\mathrm{K}+$ transport

J Plant Physiol, 171 (2014), pp. 732-742

Puig and Penarrubia, 2009

S. Puig, L. Penarrubia

Placing metal micronutrients in context: transport and distribution in plants

Curr Opin Plant Biol, 12 (2009), pp. 299-306

Ranf et al., 2008

S. Ranf, P. Wunnenberg, J. Lee, D. Becker, M. Dunkel, R. Hedrich, et al. Loss of the vacuolar cation channel, AtTPC1, does not impair $\mathrm{Ca}+$ signals induced by abiotic and biotic stresses

Plant J, 53 (2008), pp. 287-299

Rellan-Alvarez et al., 2008

R. Rellan-Alvarez, J. Abadia, A. Alvarez-Fernandez

Formation of metal-nicotianamine complexes as affected by $\mathrm{pH}$, ligand exchange with citrate and metal exchange. A study by electrospray ionization time-of-flight mass spectrometry

Rapid Commun Mass Spectrom, 22 (2008), pp. 1553-1562 
R. Rellan-Alvarez, J. Giner-Martinez-Sierra, J. Orduna, I. Orera, J.A. RodriguezCastrillon, J.I. Garcia-Alonso, et al.

Identification of a tri-iron(III), tri-citrate complex in the xylem sap of irondeficient tomato resupplied with iron: new insights into plant iron longdistance transport

Plant Cell Physiol, 51 (2010), pp. 91-102

Richau et al., 2009

K.H. Richau, A.D. Kozhevnikova, I.V. Seregin, R. Vooijs, P.L.M. Koevoets, J.A.C. Smith, et al.

Chelation by histidine inhibits the vacuolar sequestration of nickel in roots of the hyperaccumulator Thlaspi caerulescens

New Phytol, 183 (2009), pp. 106-116

Rubio et al., 2008

F. Rubio, M. Nieves-Cordones, F. Aleman, V. Martinez

Relative contribution of AtHAK5 and AtAKT1 to $K(+)$ uptake in the highaffinity range of concentrations

Physiol Plant, 134 (2008), pp. 598-608

Saito et al., 2010

A. Saito, M. Saito, Y. Ichikawa, M. Yoshiba, T. Tadano, E. Miwa, et al.

Difference in the distribution and speciation of cellular nickel between nickeltolerant and non-tolerant Nicotiana tabacum L. cv. BY-2 cells

Plant Cell Environ, 33 (2010), pp. 174-187

Sancenon et al., 2004

V. Sancenon, S. Puig, I. Mateu-Andres, E. Dorcey, D.J. Thiele, L. Penarrubia

The Arabidopsis copper transporter COPT1 functions in root elongation and pollen development

J Biol Chem, 279 (2004), pp. 15348-15355

Sanchez-Pardo et al., 2012

B. Sanchez-Pardo, M. Fernandez-Pascual, P. Zornoza 
Copper microlocalisation, ultrastructural alterations and antioxidant responses in the nodules of white lupin and soybean plants grown under conditions of copper excess

Environ Exp Bot, 84 (2012), pp. 52-60

Santi and Schmidt, 2009

S. Santi, W. Schmidt

Dissecting iron deficiency-induced proton extrusion in Arabidopsis roots New Phytol, 183 (2009), pp. 1072-1084

Sasaki et al., 2011

A. Sasaki, N. Yamaji, J.X. Xia, J.F. Ma

OsYSL6 is involved in the detoxification of excess manganese in rice Plant Physiol, 157 (2011), pp. 1832-1840

Sassi et al., 2012

A. Sassi, D. Mieulet, I. Khan, B. Moreau, I. Gaillard, H. Sentenac, et al. The rice monovalent cation transporter OsHKT2;4: revisited ionic selectivity Plant Physiol, 160 (2012), pp. 498-510

Schaaf et al., 2006

G. Schaaf, A. Honsbein, A.R. Meda, S. Kirchner, D. Wipf, N. von Wiren

AtIREG2 encodes a tonoplast transport protein involved in iron-dependent nickel detoxification in Arabidopsis thaliana roots

J Biol Chem, 281 (2006), pp. 25532-25540

Seo et al., 2012

P.J. Seo, J. Park, M.J. Park, Y.S. Kim, S.G. Kim, J.H. Jung, et al.

A Golgi-localized MATE transporter mediates iron homoeostasis under osmotic stress inArabidopsis

Biochem J, 442 (2012), pp. 551-561

Shanmugam et al., 2011

V. Shanmugam, J.C. Lo, C.L. Wu, S.L. Wang, C.C. Lai, E.L. Connolly, et al. Differential expression and regulation of iron-regulated metal transporters in Arabidopsis halleriand Arabidopsis thaliana - the role in zinc tolerance 
New Phytol, 190 (2011), pp. 125-137

Shaul, 2002

O. Shaul

Magnesium transport and function in plants: the tip of the iceberg

Biometals, 15 (2002), pp. 309-323

Shaul et al., 1999

O. Shaul, D.W. Hilgemann, J. de-Almeida-Engler, M. Van Montagu, D. Inzé, G.

Galili

Cloning and characterization of a novel $\mathrm{Mg} 2+/ \mathrm{H}+$ exchanger

EMBO J, 18 (1999), pp. 3973-3980

Shi et al., 2002

H.Z. Shi, F.J. Quintero, J.M. Pardo, J.K. Zhu

The putative plasma membrane $\mathrm{Na}+/ \mathrm{H}+$ antiporter SOS1 controls long-

distance $\mathrm{Na}+$ transport in plants

Plant Cell, 14 (2002), pp. 465-477

Siemianowski et al., 2014

O. Siemianowski, A. Barabasz, M. Kendziorek, A. Ruszczynska, E. Bulska, L.E. Williams, et al.

HMA4 expression in tobacco reduces $\mathrm{Cd}$ accumulation due to the induction of the apoplastic barrier

J Exp Bot, 65 (2014), pp. 1125-1139

Siemianowski et al., 2011

O. Siemianowski, R.F. Mills, L.E. Williams, D.M. Antosiewicz

Expression of the P-1B-type ATPase AtHMA4 in tobacco modifies $\mathrm{Zn}$ and $\mathrm{Cd}$ root to shoot partitioning and metal tolerance

Plant Biotechnol J, 9 (2011), pp. 64-74

Sinclair and Kramer, 2012

S.A. Sinclair, U. Kramer

The zinc homeostasis network of land plants 
BBA Mol Cell Res, 1823 (2012), pp. 1553-1567

Song et al., 2004

C.P. Song, Y. Guo, Q.S. Qiu, G. Lambert, D.W. Galbraith, A. Jagendorf, et al. A probable $\mathrm{Na}+(\mathrm{K}+) / \mathrm{H}+$ exchanger on the chloroplast envelope functions in pH homeostasis and chloroplast development in Arabidopsis thaliana Proc Natl Acad Sci U S A, 101 (2004), pp. 10211-10216

Song et al., 2010

W.Y. Song, K.S. Choi, D.Y. Kim, M. Geisler, J. Park, V. Vincenzetti, et al.

Arabidopsis PCR2 is a zinc exporter involved in both zinc extrusion and longdistance zinc transport

Plant Cell, 22 (2010), pp. 2237-2252

Stacey et al., 2008

M.G. Stacey, A. Patel, W.E. McClain, M. Mathieu, M. Remley, E.E. Rogers, et al.

The Arabidopsis AtOPT3 protein functions in metal homeostasis and movement of iron to developing seeds

Plant Physiol, 146 (2008), pp. 589-601

Sunarpi et al., 2005

Horie T. Sunarpi, J. Motoda, M. Kubo, H. Yang, K. Yoda, et al.

Enhanced salt tolerance mediated by AtHKT1 transporter-induced $\mathrm{Na}+$ unloading from xylem vessels to xylem parenchyma cells

Plant J, 44 (2005), pp. 928-938

Suzuki et al., 2008

M. Suzuki, T. Tsukamoto, H. Inoue, S. Watanabe, S. Matsuhashi, M. Takahashi, et al.

Deoxymugineic acid increases $\mathrm{Zn}$ translocation in $\mathrm{Zn}$-deficient rice plants Plant Mol Biol, 66 (2008), pp. 609-617

Swarbreck et al., 2013

S.M. Swarbreck, R. Colaco, J.M. Davies

Plant calcium-permeable channels

Plant Physiol, 163 (2013), pp. 514-522 
Takahashi et al., 2012a

R. Takahashi, K. Bashir, Y. Ishimaru, N.K. Nishizawa, H. Nakanishi

The role of heavy-metal ATPases, HMAs, in zinc and cadmium transport in rice

Plant Signal Behav, 7 (2012), pp. 1605-1607

Takahashi et al., 2011

R. Takahashi, Y. Ishimaru, T. Senoura, H. Shimo, S. Ishikawa, T. Arao, et al.

The OsNRAMP1 iron transporter is involved in $\mathrm{Cd}$ accumulation in rice

J Exp Bot, 62 (2011), pp. 4843-4850

Takahashi et al., 2012b

R. Takahashi, Y. Ishimaru, H. Shimo, Y. Ogo, T. Senoura, N.K. Nishizawa, et al.

The OsHMA2 transporter is involved in root-to-shoot translocation of $\mathrm{Zn}$ and

Cd in rice

Plant Cell Environ, 35 (2012), pp. 1948-1957

Tanoi et al., 2011

K. Tanoi, T. Saito, N. Iwata, N.I. Kobayashi, T.M. Nakanishi

The analysis of magnesium transport system from external solution to xylem

in rice root

Soil Sci Plant Nutr, 57 (2011), pp. 265-271

Tapken et al., 2012

W. Tapken, K. Ravet, M. Pilon

Plastocyanin controls the stabilization of the thylakoid Cu-transporting P-type

ATPase PAA2/HMA8 in response to low copper in Arabidopsis

J Biol Chem, 287 (2012), pp. 18544-18550

Tian et al., 2009

S.K. Tian, L.L. Lu, X.E. Yang, J.M. Labavitch, Y.Y. Huang, P. Brown

Stem and leaf sequestration of zinc at the cellular level in the

hyperaccumulator Sedum alfredii

New Phytol, 182 (2009), pp. 116-126 
Ueno et al., 2009

D. Ueno, N. Yamaji, J.F. Ma

Further characterization of ferric-phytosiderophore transporters ZmYS1 and HvYS1 in maize and barley

J Exp Bot, 60 (2009), pp. 3513-3520

van Kleeff et al., 2014

P.J.M. van Kleeff, N. Jaspert, K.W. Li, S. Rauch, C. Oecking, A.H. de Boer

Higher order Arabidopsis 14-3-3 mutants show 14-3-3 involvement in primary root growth both under control and abiotic stress conditions

J Exp Bot, 65 (2014), pp. 5877-5888

Vert et al., 2009

G. Vert, M. Barberon, E. Zelazny, M. Seguela, J.F. Briat, C. Curie

Arabidopsis IRT2 cooperates with the high-affinity iron uptake system to maintain iron homeostasis in root epidermal cells

Planta, 229 (2009), pp. 1171-1179

Vert et al., 2002

G. Vert, N. Grotz, F. Dedaldechamp, F. Gaymard, M.L. Guerinot, J.F. Briat, et al. IRT1, an Arabidopsis transporter essential for iron uptake from the soil and for plant growth

Plant Cell, 14 (2002), pp. 1223-1233

Very et al., 2014

A.A. Very, M. Nieves-Cordones, M. Daly, I. Khan, C. Fizames, H. Sentenac

Molecular biology of $\mathrm{K}+$ transport across the plant cell membrane: what do we learn from comparison between plant species

J Plant Physiol, 171 (2014), pp. 748-769

Voelker et al., 2010

C. Voelker, J.L. Gomez-Porras, D. Becker, S. Hamamoto, N. Uozumi, F. Gambale, et al.

Roles of tandem-pore K plus channels in plants - a puzzle still to be solved Plant Biol, 12 (2010), pp. 56-63 
Wang and $\mathrm{Wu}, 2013$

Y. Wang, W.H. Wu

Potassium transport and signaling in higher plants

Annu Rev Plant Biol, 64 (2013), pp. 451-476

Waters and Grusak, 2008

B.M. Waters, M.A. Grusak

Whole-plant mineral partitioning throughout the life cycle in Arabidopsis thaliana ecotypes Columbia, Landsberg erecta, Cape Verde Islands, and the mutant line ysl1ys|3

New Phytol, 177 (2008), pp. 389-405

White et al., 2002

P.J. White, H.C. Bowen, V. Demidchik, C. Nichols, J.A. Davies

Genes for calcium-permeable channels in the plasma membrane of plant root cells

BBA Biomembr, 1564 (2002), pp. 299-309

White and Broadley, 2003

P.J. White, M.R. Broadley

Calcium in plants

Ann Bot, 92 (2003), pp. 487-511

White and Brown, 2010

P.J. White, P.H. Brown

Plant nutrition for sustainable development and global health

Ann Bot, 105 (2010), pp. 1073-1080

Wu and Becker, 2012

B. Wu, J.S. Becker

Imaging techniques for elements and element species in plant science

Metallomics, 4 (2012), pp. 403-416

Xu et al., 2012a 
W.F. Xu, L.G. Jia, F. Baluska, G.C. Ding, W.M. Shi, N.H. Ye, et al.

PIN2 is required for the adaptation of Arabidopsis roots to alkaline stress by modulating proton secretion

J Exp Bot, 63 (2012), pp. 6105-6114

Xu et al., 2013a

W.F. Xu, L.G. Jia, W.M. Shi, F. Baluska, H.J. Kronzucker, J.S. Liang, et al.

The tomato 14-3-3 protein TFT4 modulates $\mathrm{H}+$ efflux, basipetal auxin transport, and the PKS5-J3 pathway in the root growth response to alkaline stress

Plant Physiol, 163 (2013), pp. 1817-1828

Xu et al., 2013b

W.F. Xu, L.G. Jia, W.M. Shi, J.S. Liang, F. Zhou, Q.F. Li, et al.

Abscisic acid accumulation modulates auxin transport in the root tip to enhance proton secretion for maintaining root growth under moderate water stress

New Phytol, 197 (2013), pp. 139-150

Xu et al., 2012b

W.F. Xu, W.M. Shi, L.G. Jia, J.S. Liang, J.H. Zhang

TFT6 and TFT7, two different members of tomato 14-3-3 gene family, play distinct roles in plant adaption to low phosphorus stress

Plant Cell Environ, 35 (2012), pp. 1393-1406

Yamasaki et al., 2009

H. Yamasaki, M. Hayashi, M. Fukazawa, Y. Kobayashi, T. Shikanai

SQUAMOSA promoter binding protein-like7 is a central regulator for copper homeostasis inArabidopsis

Plant Cell, 21 (2009), pp. 347-361

Yang et al., 2010

Y.Q. Yang, Y.X. Qin, C.G. Xie, F.Y. Zhao, J.F. Zhao, D.F. Liu, et al.

The Arabidopsis chaperone $\mathrm{J} 3$ regulates the plasma membrane $\mathrm{H}^{+}$-ATPase through interaction with the PKS5 kinase

Plant Cell, 22 (2010), pp. 1313-1332 
Yao et al., 2010

X. Yao, T. Horie, S.W. Xue, H.Y. Leung, M. Katsuhara, D.E. Brodsky, et al.

Differential sodium and potassium transport selectivities of the rice

OsHKT2;1 and OsHKT2;2 transporters in plant cells

Plant Physiol, 152 (2010), pp. 341-355

Yao et al., 2012

Y.N. Yao, G. Xu, D.L. Mou, J.R. Wang, J.B. Ma

Subcellular Mn compartation, anatomic and biochemical changes of two

grape varieties in response to excess manganese

Chemosphere, 89 (2012), pp. 150-157

Yokosho et al., 2009

K. Yokosho, N. Yamaji, D. Ueno, N. Mitani, J.F. Ma

OsFRDL1 is a citrate transporter required for efficient translocation of iron in rice

Plant Physiol, 149 (2009), pp. 297-305

Yuan et al., 2011

M. Yuan, X. Li, J. Xiao, S. Wang

Molecular and functional analyses of COPT/Ctr-type copper transporter-like gene family in rice

BMC Plant Biol, 11 (2011), p. 69

Zhang et al., 2010

J.L. Zhang, T.J. Flowers, S.M. Wang

Mechanisms of sodium uptake by roots of higher plants

Plant Soil, 326 (2010), pp. 45-60

Zhang et al., 2013

J.L. Zhang, T.J. Flowers, S.M. Wang

Differentiation of low-affinity $\mathrm{Na}+$ uptake pathways and kinetics of the effects of $\mathrm{K}+$ on $\mathrm{Na}+$ uptake in the halophyte Suaeda maritima

Plant Soil, 368 (2013), pp. 629-640 
Zhang et al., 2011

W.J. Zhang, J.P.C. To, C.Y. Cheng, G.E. Schaller, J.J. Kieber

Type-A response regulators are required for proper root apical meristem function through post-transcriptional regulation of PIN auxin efflux carriers

Plant J, 68 (2011), pp. 1-10

Zhang et al., 2012

Y. Zhang, Y.H. Xu, H.Y. Yi, J.M. Gong

Vacuolar membrane transporters OsVIT1 and OsVIT2 modulate iron

translocation between flag leaves and seeds in rice

Plant J, 72 (2012), pp. 400-410

Zhao et al., 2012

H.J. Zhao, L.Q. Wu, T.Y. Chai, Y.X. Zhang, J.J. Tan, S.W. Ma

The effects of copper, manganese and zinc on plant growth and elemental accumulation in the manganese-hyperaccumulator Phytolacca americana J Plant Physiol, 169 (2012), pp. 1243-1252

Zhao et al., 2008

J. Zhao, N.H. Cheng, C.M. Motes, E.B. Blancaflor, M. Moore, N. Gonzales, et al. AtCHX13 is a plasma membrane $\mathrm{K}+$ transporter

Plant Physiol, 148 (2008), pp. 796-807

Zheng et al., 2012

L.Q. Zheng, N. Yamaji, K. Yokosho, J.F. Ma

YSL16 is a phloem-localized transporter of the copper-nicotianamine complex that is responsible for copper distribution in rice

Plant Cell, 24 (2012), pp. 3767-3782

Zörb et al., 2014

C. Zörb, M. Senbayram, E. Peiter

Potassium in agriculture - status and perspectives

J Plant Physiol, 171 (2014), pp. 656-669 
Zorrig et al., 2011

W. Zorrig, C. Abdelly, P. Berthomieu

The phylogenetic tree gathering the plant $\mathrm{Zn} / \mathrm{Cd} / \mathrm{Pb} / \mathrm{Co}$ P1B-ATPases appears to be structured according to the botanical families

C R Biol, 334 (2011), pp. 863-871 